Article

\title{
An Efficient Solitary Senior Citizens Care Algorithm and Application: Considering Emotional Care for Big Data Collection
}

\author{
Jun-Ho Huh \\ Department of Software, Catholic University of Pusan, Busan 609-757, Korea; \\ 72networks@pukyong.ac.kr or 72networks@cup.ac.kr
}

Received: 27 October 2018; Accepted: 26 November 2018; Published: 27 November 2018

check for updates

\begin{abstract}
The issue of solitary senior citizens dying alone has become serious in advanced countries where the average lifespan of their citizens is continuously extending due to improved health care and diet. Such unattended deaths are considered to be one of the major issues pertaining to the ever-growing number of senior citizens so that many research studies have been conducted to find a solution to mitigate the situation. The framework proposed in this study allows monitoring of electric power consumption patterns of solitary senior citizens. At the same time, a test bed was constructed to estimate the performance of the framework. The results from the test bed experiment revealed that the framework was effective, flexible, and expandable for actual implementation. This framework is the product of these research studies describing individual designs and the method of implementing them for actual application. This research has confirmed that the framework for an extendable solitary senior citizens care system can be designed and implemented at low cost and the operations between system components worked smoothly while interacting flexibly. In particular, the rate of these old people dying alone in poor areas was above normal so that the proposed system would be quite meaningful to society as it helps in monitoring their safety by locating the whereabouts of those people with dementia or checking their daily routines, for example.
\end{abstract}

Keywords: solitary-death sensing; emotional care; senior citizens care algorithm; senior citizens care; health care; java; application; software engineering; embedded system; solution

\section{Introduction}

The proportion of senior citizens over 65 years old is increasing all over the world and according to Statistics Korea, it is expected to increase from $7.5 \%$ in 2010 to $16.2 \%$ in 2050 [1]. In the Republic of Korea, the proportion has increased from 3.1\% (1970) to $11.8 \%$ (2012) and is expected to reach $37.4 \%$ by the end of 2050 . Thus, it is evident that the aging population is growing rapidly. In addition to the economic problem, one of the major difficulties being experienced by these people is health, which accounts for $39.8 \%$ of the current problems experienced by the elderly [2]. Therefore, they need to be cared for by their guardians or the government to maintain good health. They often have diseases such as high blood pressure and/or diabetes and their chance of facing a safety-related accident in their daily lives is quite high. In particular, since solitary senior citizens are usually living independently, they require continuous monitoring/observation, but in many cases, they are unable to let others know about an emergency when necessary. To prevent such a situation in their daily lives, a system has been studied which monitors the daily activities of solitary senior citizens and notifies emergency services about an emergency. The recent development of Information Technology (IT) brought convenience to people around the world and the ubiquitous environment where people can receive adequate assistance is no longer strange to us. 
Senior citizens are more vulnerable to illness than young people and their poor health conditions can have a more adverse impact on them, resulting in chronic diseases and weakened physical or mental strength which disrupts their daily lives. The health conditions can be attributed not only to a person's age or a disease but also affects senior citizens' self-sufficiency and physical and social activities. The research conducted by Demiris and his team [3] has shown that senior citizens often experience their activities being limited by physical problems such as weakened or loss of sight, hearing, sense of touch, memory, balance, reading skills, control ability, understanding of information provided with some additional impeditive elements (e.g., Television (TV) news including BackGround Music (BGM)s or searching through internet sites containing many advertisements), and ability to operate a Personal Computer (PC) with a mouse [3].

According to Pattenden [4], the elements which should be considered for a smart home design include available and adequate technologies which encompass a wide range of technical requirements to achieve reliable and quality service, level of energy consumption and its management, appropriate equipment, and the level of convenience of the communication system to be used. He further pointed out that the social requirements and user requirements should be satisfied in addition to these technological aspects. The former includes compatibility with existing services, health care, safety, protection of privacy, social care, and information services, whereas the latter involves cost balance, interface, friendly environment, personalization, and comfort and simplicity of the application. Also, from the perspective of smart-home owners, occupants of the buildings, or investors, the range of requirements could be widened as well, extending to the occupants' needs and expectations, user interface, safety, parameters in a broad home environment and local networks, types of service demands and the method of service application, usage of current or expected technical equipment, basic principles of system architecture, and up-to-date information concerning installation, components, operation, and maintenance of all the hardware and software being used or planned.

These considerations can be managed with quality management of the home environment (e.g., lighting and temperature control, etc.), including energy management and warnings, remote measurement of energy usage or water consumption, information and control systems including in-home headcount, monitoring of senior citizens' health and safety, security Closed Circuit Television (CCTV) system, intrusion detection, maintenance by remote diagnosis, education (e-learning), communication with caregivers or relatives/family members or social and health staff via video-conference, and provision of entertainment preferred by them (Zálešák [5]).

Evaluation of technologies to be used in a smart building is essential for designing a bus system. The respective functions and designs should be studied carefully along with the residents' specific needs or demands. It is considered that the optimal height of an intelligent building would be around 5 stories high for senior citizens. Demiris [6] proposed two approaches which can mitigate the inconveniences felt by senior citizens when they are being monitored for their daily activities: Distributed Direct Sensing (DDS) employs a number of sensors for monitoring, but this system focuses on overall activities without considering their privacy and private spaces. By contrast, Infrastructure Mediated Sensing (IMS) pays more attention to these elements but performs almost the same function as DDS, utilizing existing power lines. A series of past and present studies agrees that the needs of senior citizens are not being fully researched so that designing an optimal Information \& Communication Technology (ICT) system for them has yet to be achieved for smart homes. Koch [7] especially emphasized the necessity of interdisciplinary research on the application of information technologies for various age groups.

In addition to the rapid decrease (social workers) in population and the aging population, the problem of unattended deaths is considered to be an urgent social issue that should be effectively dealt with. This type of death has been observed in advanced countries like the Republic of Korea (ROK) and Japan so that respective governments are trying to find an effective way of monitoring and preventing it. A framework based on Internet of Things (IoT) and Power Line Communication (PLC) technologies that can provide an efficient way of monitoring the changes in the power usage of 
a solitary senior citizen is introduced in this study. Some of the research findings from the author's previous studies [8-10] were considered when constructing the framework and the test bed, which was established based on the scenarios developed for the three layers of seven-layer OSI (Figure 1) where the scope of the test bed experiment was described (Figure 1).

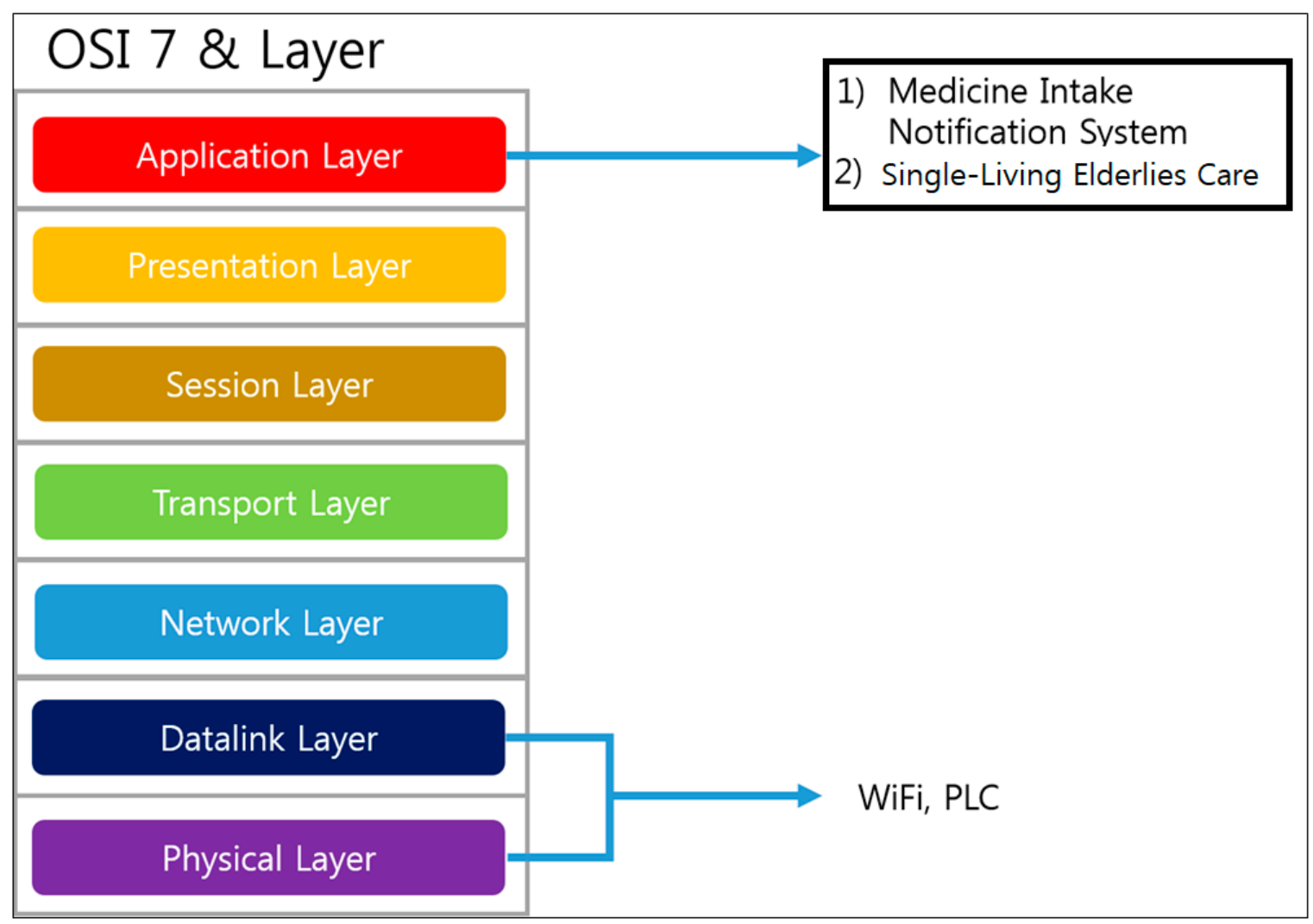

Figure 1. The Range of Test Bed Experiments of the Framework for the Single-Living Senior Citizens Care.

Also, for the last decade, the lonely deaths of solitary senior citizens have been one of the major issues in the Republic of Korea. The number of senior citizens is increasing rapidly all over the world and the studies on the methods of monitoring such deaths are being conducted actively in countries such as the US and Japan.

An algorithm considering the emotional care of senior citizens is proposed in this study along with a Java-based Android application to achieve more attentive emotional care, not just simply monitoring whether their lives are being sustained as the previous solutions have focused on. Two types of $220 \mathrm{~V}$ (standard voltage in the Republic of Korea) Power Line Communication (PLC)-based communication scenarios have been respectively developed in the Datalink and Physical layers for a period of two years to validate the effectiveness and scalability of the framework. At the same time, an IoT-based monitoring system was developed for gravesites or memorial parks using the PLC technology, which is quite effective in mountainous areas. In the Application layer, an application for solitary senior citizens was developed with Java Android.

This study is an extended version of the research work A Framework and Test Bed for Single-Living Senior Citizens Care: Gravesite Access Monitoring presented in the past proceeding [2]. A design methodology for Unified Modeling Language (UML)-based programming has been newly added in addition to the Android application which focuses on the emotional care for the solitary senior citizens. I have attempted this program to be potentially convenient for collecting big data, user-friendly and useful to the administrators/social workers/data scientists. 
This research work is organized as follows: the background of research and related research and the design of target system for single-living senior citizens care installation environment are introduced separately in Sections 2-4, whereas the framework of solitary senior citizens care and the Java Android UML and application are described in Sections 5 and 6, respectively, followed by the conclusion of the study in Section 7.

\section{Background of Research}

According to the analysis by Health Insurance Review \& Assessment Service (2014), the solitary senior citizens over 70 years old accounted for $22.2 \%$ of those who had received a treatment for depression between 2009 and 2013 and this was the highest level in all age groups, followed by $50 \mathrm{~s}$ $(21 \%)$ and $60 \mathrm{~s}(17.4 \%)$. This meant that 6 out of 10 older adults over 50 had received the depression treatment, and when compared with patients under $20(4.6 \%)$ and in their $20 \mathrm{~s}(7.7 \%)$, the difference is quite large. As a sort of a mental disease, depression involves somnipathy, anxiety, or decrease in concentration or sexual desire and the patients may become suicidal. The government authorities are expanding their welfare policy to solve such a problem, but as the number of social workers who can take care of these solitary senior citizens is limited and most of the services they are offering are focusing on the safety issues, these people cannot be taken care of sufficiently. Thus, the necessity of a new platform which can reach out to them has been required. The statistics of the National Statistical Office revealed that the number of deaths by suicide was 14,427 in 2013, which means that roughly 40 people commit suicide in a day and this occupies the highest place in all of the suicide rates of Organization for Economic Cooperation and Development (OECD) countries.

As this problem became increasingly serious, the Republic of Korea (ROK) government started various types of social services. A typical one is 'Safety-Checking Service' where caregivers employed by the government are to contact solitary senior citizens regularly and check their present conditions. The 'Emergency Safety-Checking Service' is being offered for the solitary senior citizens over 65 years old as well, to deal with some of the emergency situations. The sensors that detect gas leaks, fire, abnormal activities, or other emergencies have been installed in their homes and any threatening incidents will be reported to the caregivers or relevant authorities automatically.

However, most of these services are still focusing on the physical aspects so that in order to make their service more effective, an emotional approach should be considered.

\section{Related Research}

\subsection{ADL (Activities of Daily Living)}

It has been proven that the rapid development of the pharmaceutical and healthcare fields has contributed to the consistent but fast growth of the aging population in most advanced countries all over the world. For instance, statistics show that approximately 49.2 million US citizens $(15.2 \%)$ and 98.0 million EU residents (19.2\%) were over 65 years old (senior citizens) in 2016 [11,12] and the US's Administration on Aging ( $\mathrm{AoA}$ ) [13] estimated that $85 \%$ of these senior citizens were living alone. The infirmity, dementia, chronic diseases, and many other illnesses are still affecting solitary senior citizens and have been some of the major societal problems. Each country is introducing a series of policies to counteract the problems, but currently not many are satisfied. Meanwhile, Activities of Daily Living (ADL) is a set of self-caring activities required for solitary senior citizens and there are two major types of ADLs: Basic ADL (BADL) involves the activities that require simple physical movements (e.g., functional mobility, self-feeding, toilet hygiene, etc.) whereas Instrumental ADL (IADL) includes rather more complex cognitive movements (e.g., meal preparation, keeping the time for taking prescribed medicines, shopping alone, etc.) [14-16]. The practice framework issued by the American Occupational Therapy Association (AOTA) reported that both types of ADLs can be defined as the behaviors of two out of eight broad categories of "areas of occupation" people engage in [17] and the level of independence in these activities are positively correlated with people's health and 
well-being [18]. Previous studies have confirmed that both physical and cognitive disorders due to aging or diseases are likely to disrupt senior citizens' BADL and IADL [19-21] and their research further confirmed that approximately $44 \%$ of senior citizens in the US were having trouble performing at least one or more movements defined in either ADL [22]. Particularly, since IADL requires a suitable level of cognition, the movements could degenerate following the onset of dementia [23]. For this reason, monitoring and recognizing the worsening of IADL performance would be useful in diagnosing a mild cognitive impairment (MCI), which is an intermediate stage between the expected cognitive decline during the normal aging process and a more serious decline due to dementia [23-25].

It has become a common practice for clinicians and therapists to monitor a senior citizen's ADL performance with a variety of evaluation tools, including Katz ADL Scale in clinical settings [16] or self-reported activities at home [26], to grasp the patient's aging or disease progression. However, in most cases, the examination during a senior citizen's clinic visits may not provide timely data for early intervention or preventive care, while the self-reported data may not be reliable, especially if the senior citizen's cognitive function is deteriorating. To address some of these issues, many clinicians have started turning to a remote home ADL monitoring system utilizing some sensor-based monitoring technologies (e.g., wearable motion or environment detection system, camera/CCTV-based monitoring, etc.) $[27,28]$.

Meanwhile, ADLR attempts to identify the ADL events and patterns as a basis for ADL monitoring. A patient's daily activities are carried out in turns or in a disorderly manner, having a respective temporal pattern and in some respects, the complex activities can be considered as a sequential combination of simple activities so that a temporal and hierarchical ADL decomposition approach would potentially help understand the characteristics and semantics of ADLs [29]. Normally, three ADL recognition behaviors correspond with the hierarchy: locomotion, gesture, and complex activity. The complexity of these behaviors and the amount of information required for recognizing the ADLs increase following the locomotion to complex activity. Locomotion includes human body motions, such as walking, standing, and sitting. Only body motion information is required to recognize locomotion. Gestures are also referred to as a middle-level ADL (ML-ADL), consisting of physical reciprocal actions between humans and objects.

An example can be found in the task of closing a drawer, where some temporal interaction patterns of human and object motion information can be identified during the action of pushing and sliding the drawer, which aids in recognizing ML-ADLs. High-level ADLs (HL-ADLs) are complex activities consisting of temporal sequences of gestures. An example can be found when a person tries to have a cup of coffee, where he/she has to prepare some coffee powder and a cup, operate the coffee maker, pick up and drink the coffee, and then wash the cup at the end. The HL-ADL recognition could be more difficult as it requires some semantics for the target motions (i.e., the temporal pattern of ML-ADLs and/or locomotion). Contextual information such as environment information of the HL-ADL, the object's location, room setting, temperature, and luminance are also key to recognizing the HL-ADL. It has been proven that modern sensing technology can provide some promising solutions for collecting these various types of information for ADLR. Three types of sensors have been used in past ADLR studies: environment/object, motion, and camera sensors. Environment sensors like object triggers, on/off switches, infrared door sensors, and pressure sensors were attached to the objects or installed in a specific place (e.g., floor, walls, etc.) to record the condition of an object or environmental changes [29-31].

Environmental sensors determine and provide the location or the information of an object while the ADL activity is being performed, whereas the motion sensors, including accelerometer, gyroscope, and magnetometer, can be used to record the movements of an object or a human movement. Normally, a single object motion sensor is sufficient to collect the movement information of the target object. Meanwhile, for humans, a series of wearable sensors can be attached to different body locations to collect comprehensive human motion data $[29,32,33]$. Cameras can capture the complete motion semantics required for recognizing all levels of ADLs [34] but they are often too intrusive to implement 
in real-world settings [35]. These sensors' ability to collect detailed activity information also brings forth several challenges. Individual sensors are able to collect a large volume of data swiftly. For instance, a wearable motion sensor can record 20 to 100 data points per second, resulting in 1.7 to 8.6 million records per day, exceeding a human's cognitive processing capability. Besides, the data collection capacity and the data collected by environment/object and motion sensors have unique characteristics that should be considered when creating an ADLR system. Most environment sensors generate single-channel data (e.g., the on/off state and pressure described in Figure 2), whereas most wearable and object motion sensors collect multichannel data (e.g., acceleration on $x, y$, and $z$ axes). The data value of the former can be either discrete (e.g., on/ off states in Figure 2) or continuous (e.g., the pressure reading in Figure 2). By contrast, the data collected by most multichannel sensors are continuous. In any case, the data on different channels comprehensively depicts the same activity [36].

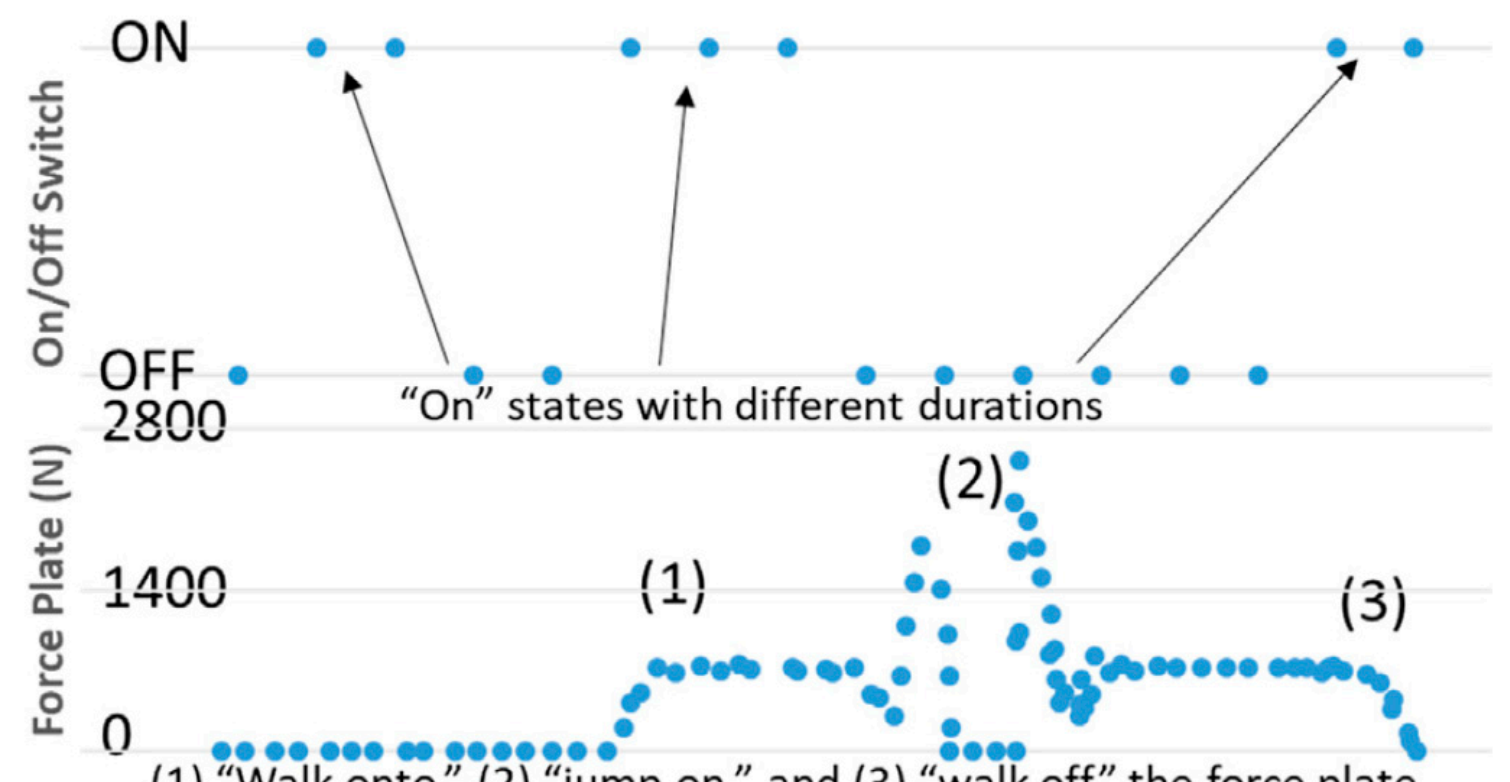

(1) "Walk onto," (2) "jump on," and (3) "walk off" the force plate

Figure 2. Discrete and Continuous Sensor Data Collected from the On/Off Switch and Force Plate.

Due to the differences between sensors and data types, previous studies concentrated on developing an ADLR system for a specific sensor type and configuration. For this reason, it has been difficult to develop such systems with other sensor types and configurations. For example, ADLR systems based on counting discrete sensor events cannot adopt multichannel sensors which record continuous values, like accelerometers. Regardless of sensor types or their combinations, most of the major ADLR studies often relied on a machine-learning algorithm to recognize ADLs. Such a method has been preferred by researchers as they are able to capture patterns in a high volume of data, which are often difficult to find manually.

\subsection{Senior Citizens Care}

Following the continuous development of IT and modern people's increased interest in their health, the number of studies attempting to combine IT technology with the healthcare system is continuing. Systems which allow the measuring of one's health condition are being developed and improved rapidly. The wireless ECG unit developed by Korea Electrotechnology Research Institute (KERI) can transmit measurement data to smart devices so that hospitals are able to recognize a patient's condition and use the data to provide remote medical service (telemedicine) or emergency treatment [37].

In foreign countries, Honeywell HomMed has commercialized a monitoring system which can measure the current condition of a patient and monitor him/her around the clock in a central 
observation center [38]. Also, there are studies which have performed research on modeling a patient's or the senior citizen's daily activity patterns with sensors. Among them, G. Virone has proposed a method which can create a $24 \mathrm{~h}$ cycle life pattern of a resident based on his/her movement patterns [39-41]. Based on Virone's finding that a person's daily activity pattern is periodically repeated, he has proposed a method called Circadian Activity Rhythm (CAR) which represents the time of a resident's repeated stay in a residential space as information in his study. Also, the life pattern of a solitary senior citizen was identified and modeled in the study by Sun-Woo Lee [42]. Additionally, there are studies that observed a person's condition by letting him/her wear a monitoring system (e.g., watch or ring-type measurement sensors) directly to measure blood pressure or body temperature, which is transmitted and managed for medical treatment by his/her doctor [43-45]. By contrast, there are also studies which observe senior citizens indirectly without wearable sensors. In-Mee Soh et al. [46] performed a study where an emergency situation can be recognized based on camera image information and inclination data. Dal-Ho Song et al. [47], Jae-Bok Jang et al. [48], and Jung-Hee Lee et al. [49] have monitored emergency situations using various types of sensors and creating a network in a ubiquitous environment. Meanwhile, studies on emergency recognition systems have been performed by Sang-Hyun Park et al. [50], Jong-Ho Choi et al. [51], and Ju-Young Goh et al. [52]. Among them, Ju-Young Goh et al. [53] have proposed a monitoring system which recognizes an emergency situation of a solitary senior citizen based on both direct and indirect monitoring methods.

As such, although there have been many studies related to the senior citizen's care service, this is the first attempt in which a design methodology for UML-based programming has been newly added in addition to the Android application which focuses on the emotional care for solitary senior citizens. We have made this program to be potentially convenient for collecting big data, user-friendly, and useful to the administrators/social workers/data scientists.

To summarize the main features which make this approach a unique solution:

- $\quad$ The proposed IoT-integrated, power-consumption-monitoring model utilizes the PLC technology instead of existing wired/wireless communication technology to avoid additional installation costs involving manpower and equipment.

- This system emphasizes 'emotional care' of solitary senior citizens rather than just monitoring their current situation.

- Besides the cost-effectiveness and the efficiency of the system, its scalability and flexibility allow it to be used for the other applications.

- $\quad$ For the above reasons, a successful commercialization can be expected.

This study aims to derive some meaningful or significant results from the big data analysis performed with the application which has been designed and implemented to put more weight on the emotional aspects of senior citizens living alone.

\section{Design of Target System for Single-Living Senior Citizens Care Installation Environment}

The number of senior citizens is increasing rapidly all over the world and studies on the methods of monitoring such deaths are being conducted actively in countries such as the US and Japan [54]. An algorithm considering the emotional care of senior citizens is proposed in this study along with a Java-based Android application to achieve more attentive emotional care, not just simply monitoring whether their lives are being sustained as the previous solutions have focused on. A simplified version of this system was created to test the effectiveness (Figure 3). 


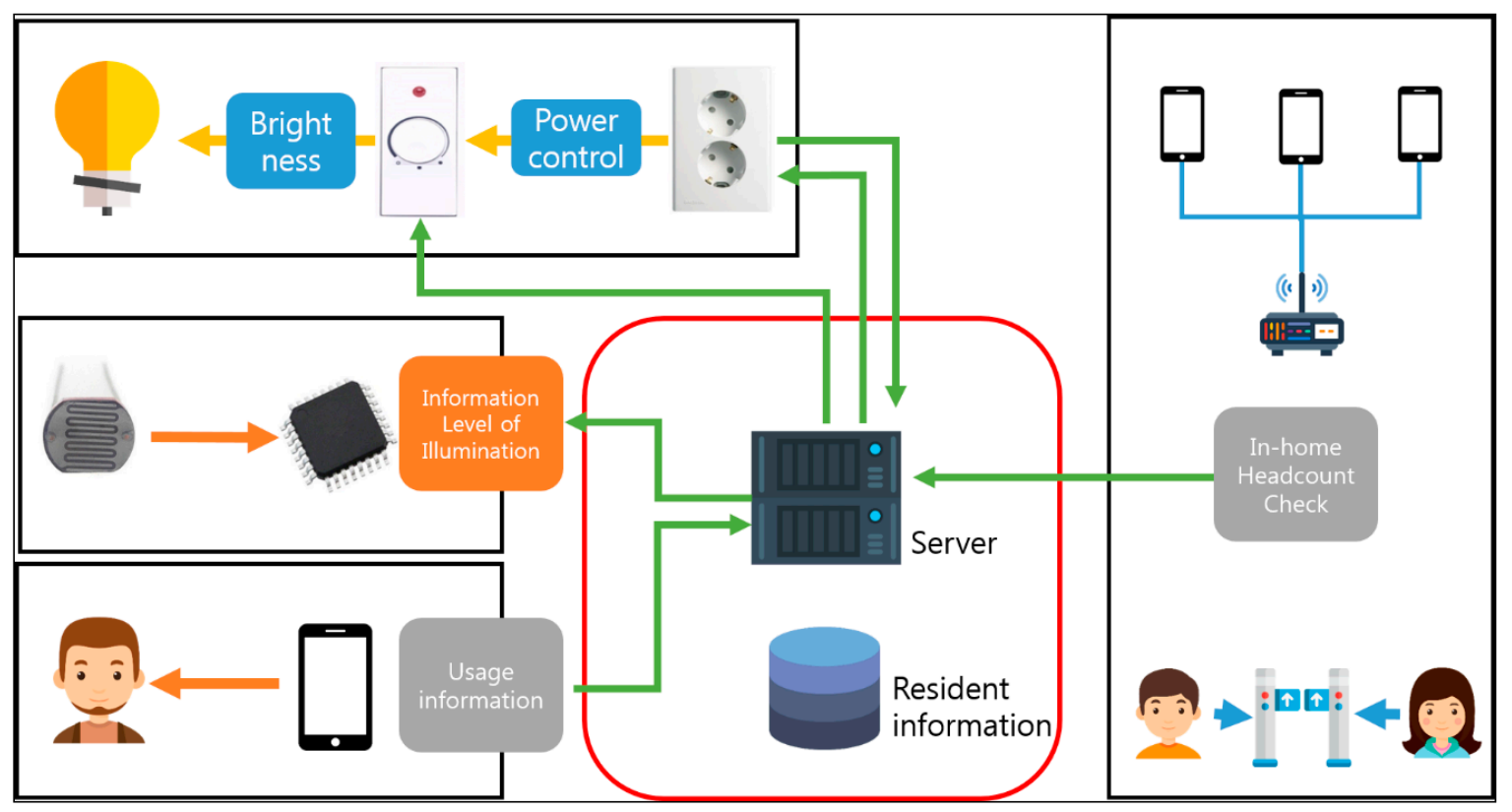

Figure 3. Functional System Diagram.

The functional diagram in Figure 4 shows the data transmission process from the household appliances to the solitary senior citizen's care system via the home server.

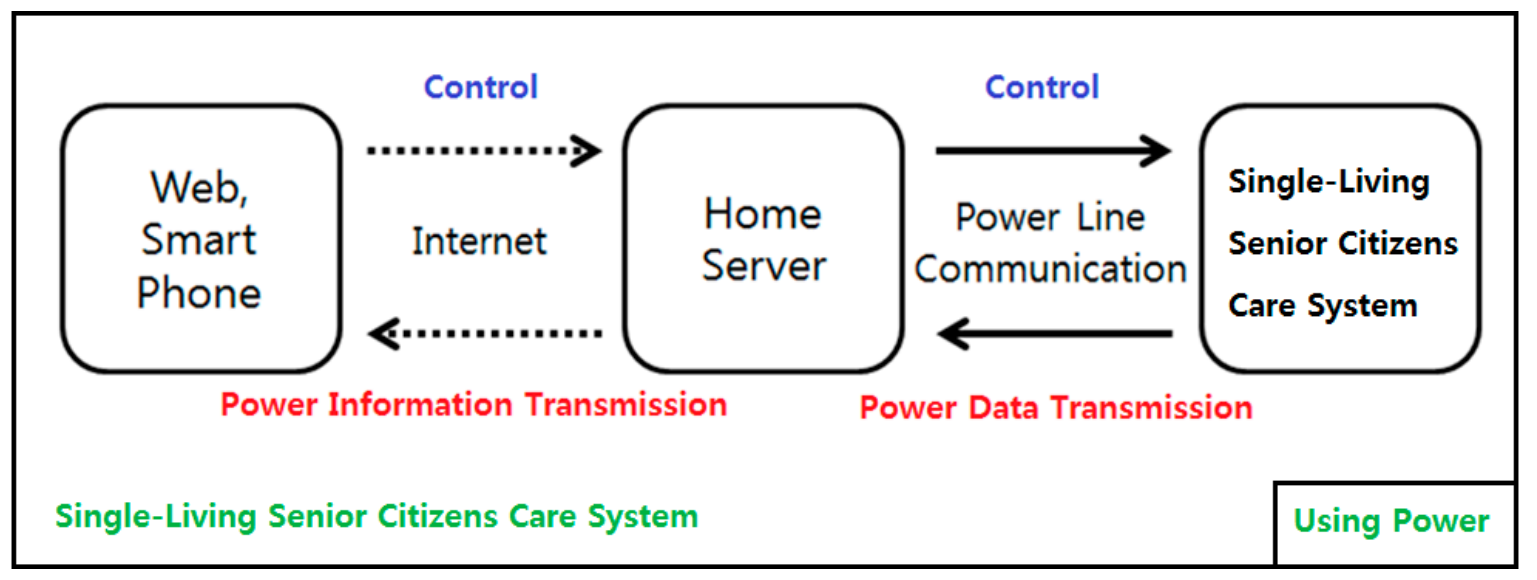

Figure 4. A Functional Diagram of the System (Scenario 1).

Individual power consumption statuses are monitored by this $220 \mathrm{~V}$ system where a PLC module and a power usage calculation/control module are embedded together. The home server analyzes the data transmitted from the care system to detect individual appliance's power-use pattern and optimizes it with AI (Artificial Intelligence) or informs the user of his/her daily, monthly, current, and past power usage of a particular appliance. Such data can be compared with other users' data to evaluate the power efficiency of household appliances. Another advantage of this system is that the user's power consumption can be managed by AI or remote control. All the appliances can be monitored by the installed PLC-based system.

The system layout is shown in Figure 5 where PLC-based data exchanges are being carried out between the serially connected home server and Arduino board. The power usage is accumulated every three minutes and then stored in a MySQL database. All the elements in this design are interfaced with PHP. 


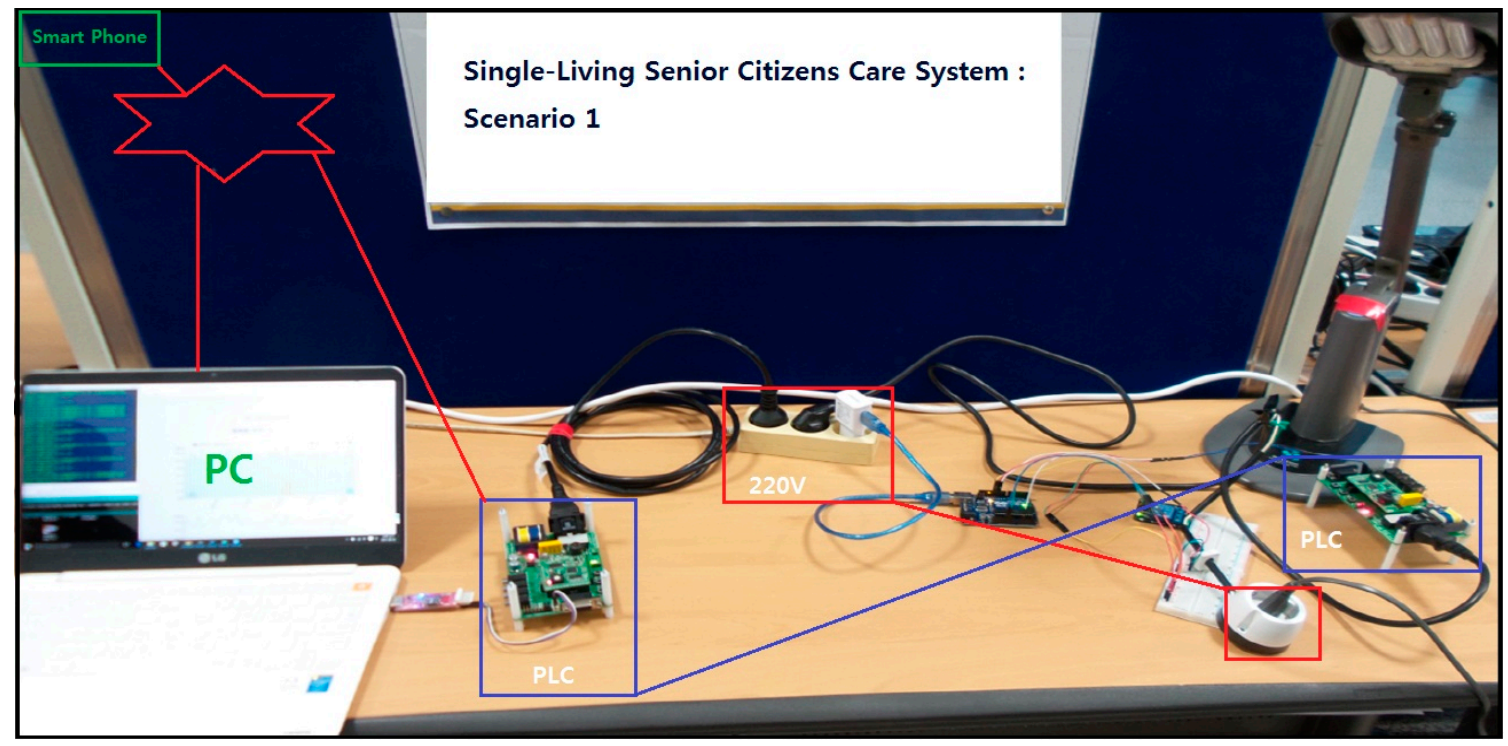

Figure 5. Scenario 1 (220 V Two PLC).

Figure 6 is a more detailed functional diagram of the system where data is exchanged between the watt-hour meter, main server, and individual electronic devices through an exclusive PLC modem so that a separate communication line is not required. The communications between the main server and the user's smart device are carried out through the internet connection. At this time, the number of people in the home can be easily determined if all of their smartphones are connected to the Wi-Fi system in the house. The watt-hour meter communicates with the main server through the PLC modem as other externally connected electronic devices which are normally controlled by their own respective operating programs.

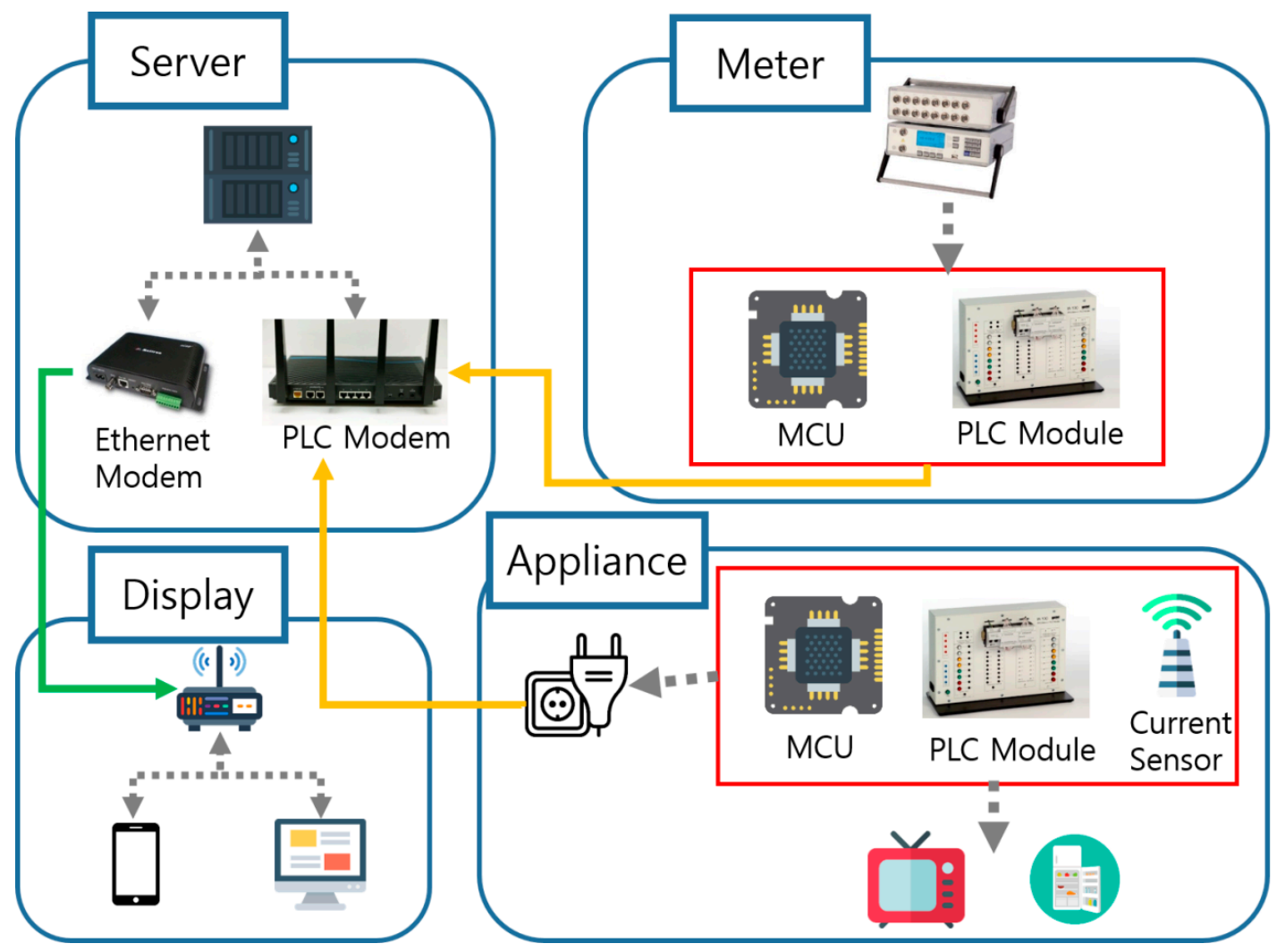

Figure 6. A Complete Functional Diagram. 
The mechanism of monitoring possible solitary deaths of solitary senior citizens is described in Figure 7 where the number of people accessing the network through the PLC system or the Wi-Fi system is counted by the server on a real-time basis. If the number remains the same for a certain period of time, a warning message is sent to the designated family member(s) or a local emergency center to let them know that the resident, a solitary senior citizen in this case, is possibly unattended. On the other hand, if the number has changed, the system will make a judgment as to whether the network was accessed by the resident him/herself or the visitors. When the system finds that there have not been any visitors for more than three or four days, a 'Visit' request is sent to the same parties, advising them to visit the household and observe the situation. Such a monitoring process can be achieved with smartphones or other smart devices.

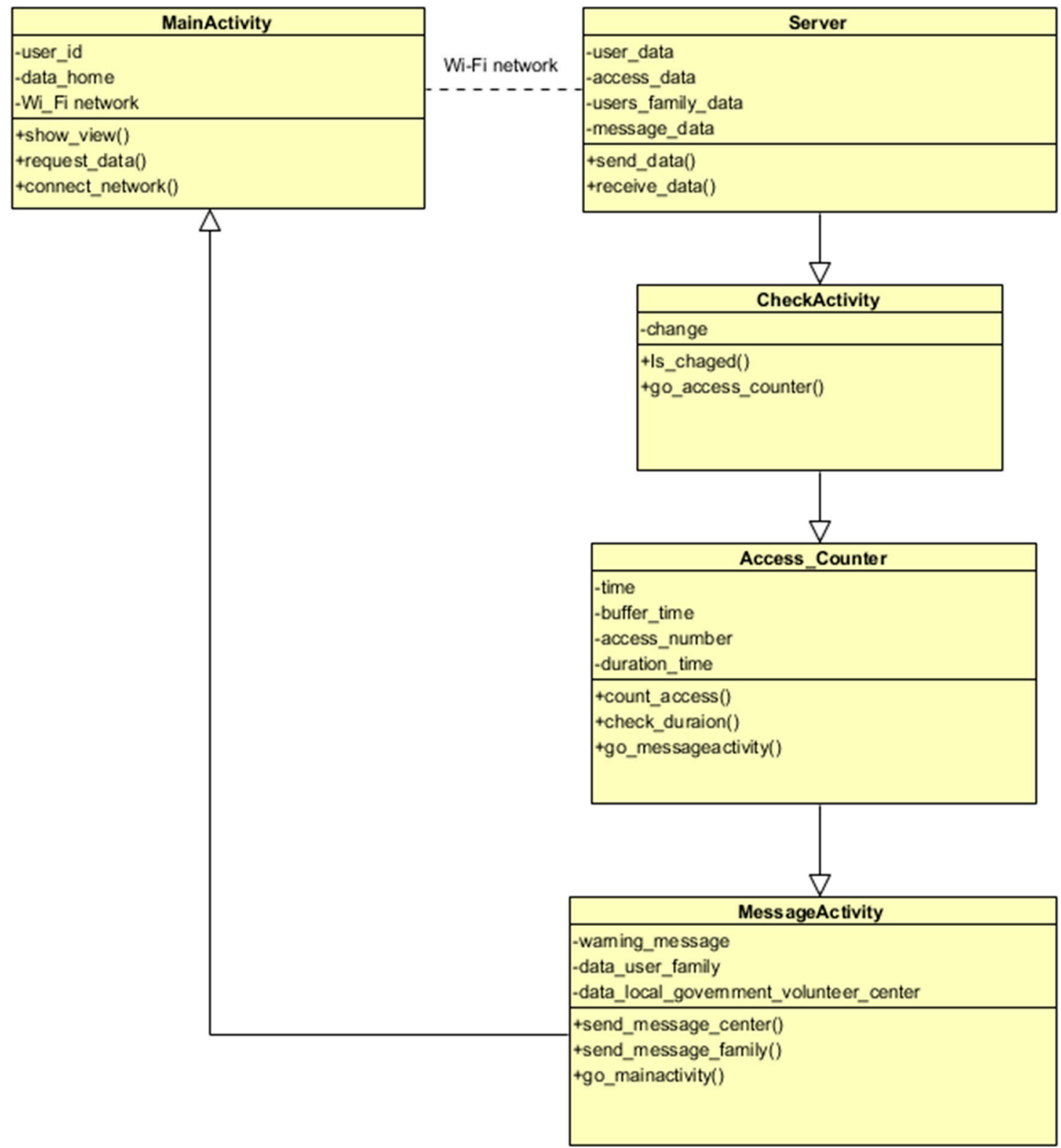

Figure 7. Solitary Deaths Monitoring Mechanism for Single-Living Elderlies Java Android UML.

In-home Headcount Checking UML is described in Figure 8 where the resident's own IP address is designated as H_ip and the router IP address is stored as $\mathrm{N} \_$ip when he/she attempts access via Wi-Fi. Then, if these two addresses are the same, 'Count' will be increased by one, or returns to the initial mode if they are not the same. On the other hand, if it is determined that the internet connection 
has been interrupted, the count is decreased by one when the addresses are the same, or the counting process stops if they are not identical. The 'Count' specifically refers to the number of residents accessing the internet through the household Wi-Fi system.

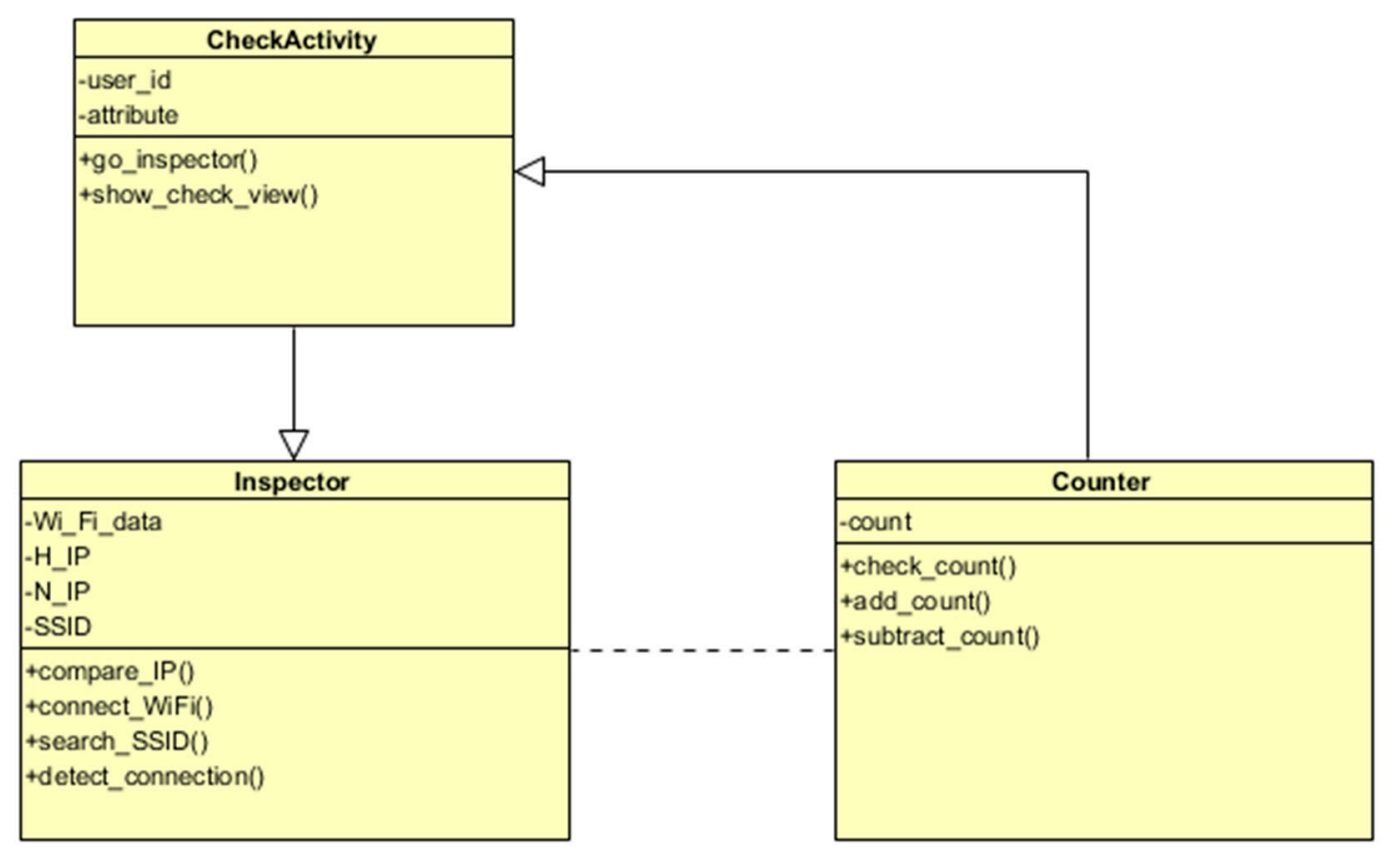

Figure 8. In-Home Headcount Checking Java Android UML.

\section{The Framework of Solitary Senior Citizens Care: Considering Emotional Care}

For the study, poor communities in the ROK were selected as a typical environment in which the neglected class of people including solitary senior citizens was living. Most of the time, only electricity and water supply are available in these areas and internet services are rarely provided. Thus, a monitoring solution for solitary senior citizens has been developed by constructing a network using a power line communication (PLC) system which can be conveniently installed in old houses at low cost and implementing an Android application.

A scalable framework was designed and implemented in this study and the result of the test bed experiment revealed that it worked efficiently and flexibly.

Figures 9 and 10 show Scenario 1 and Scenario 2 for the framework of solitary senior citizens care system, respectively. Two $220 \mathrm{~V}$ PLC modules were used for the former while three PLC modules were applied for the latter to monitor the Wi-Fi access of solitary senior citizens when they are at home. 


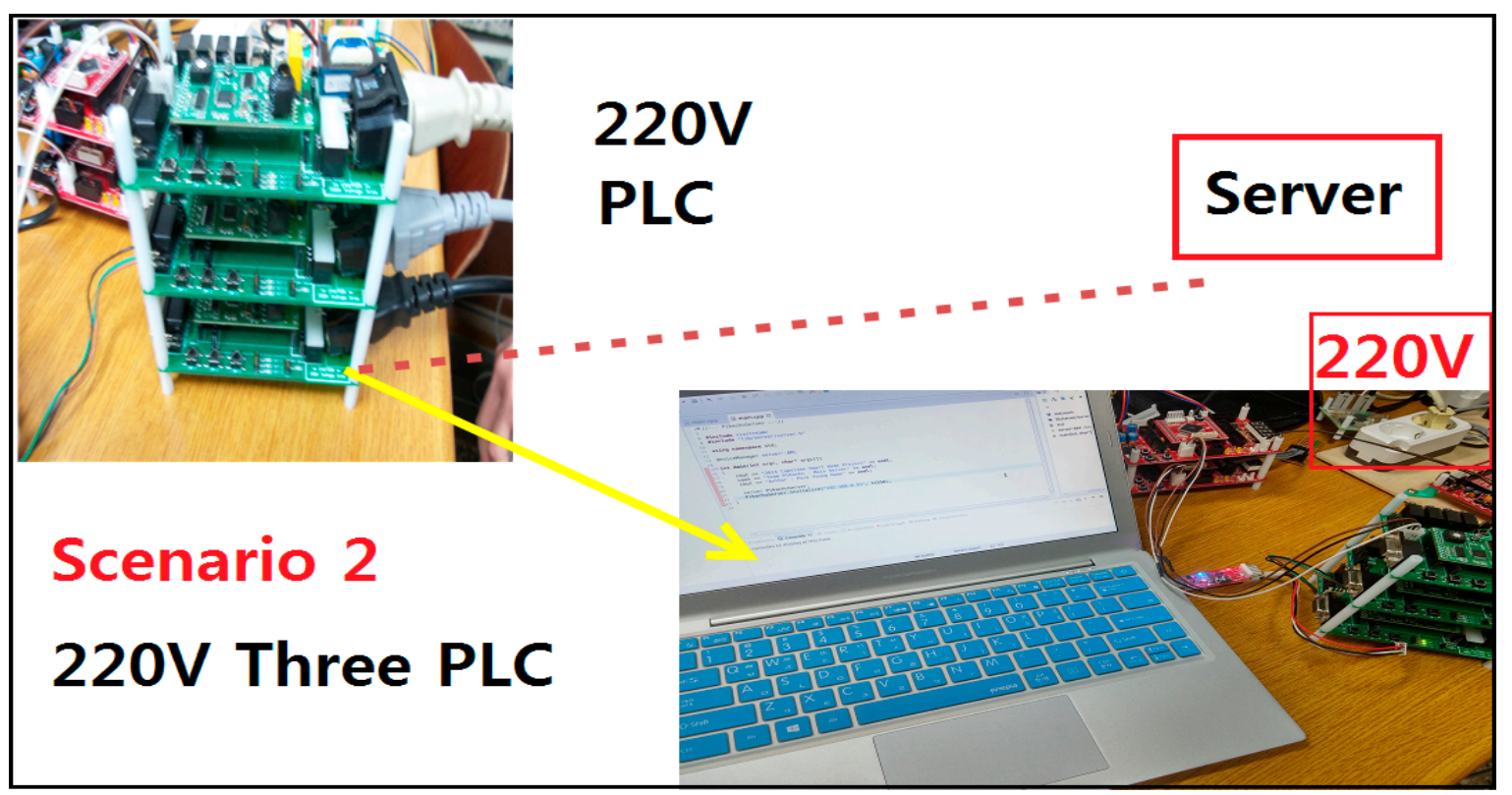

Figure 9. Scenario 2 (220 V Three PLC).

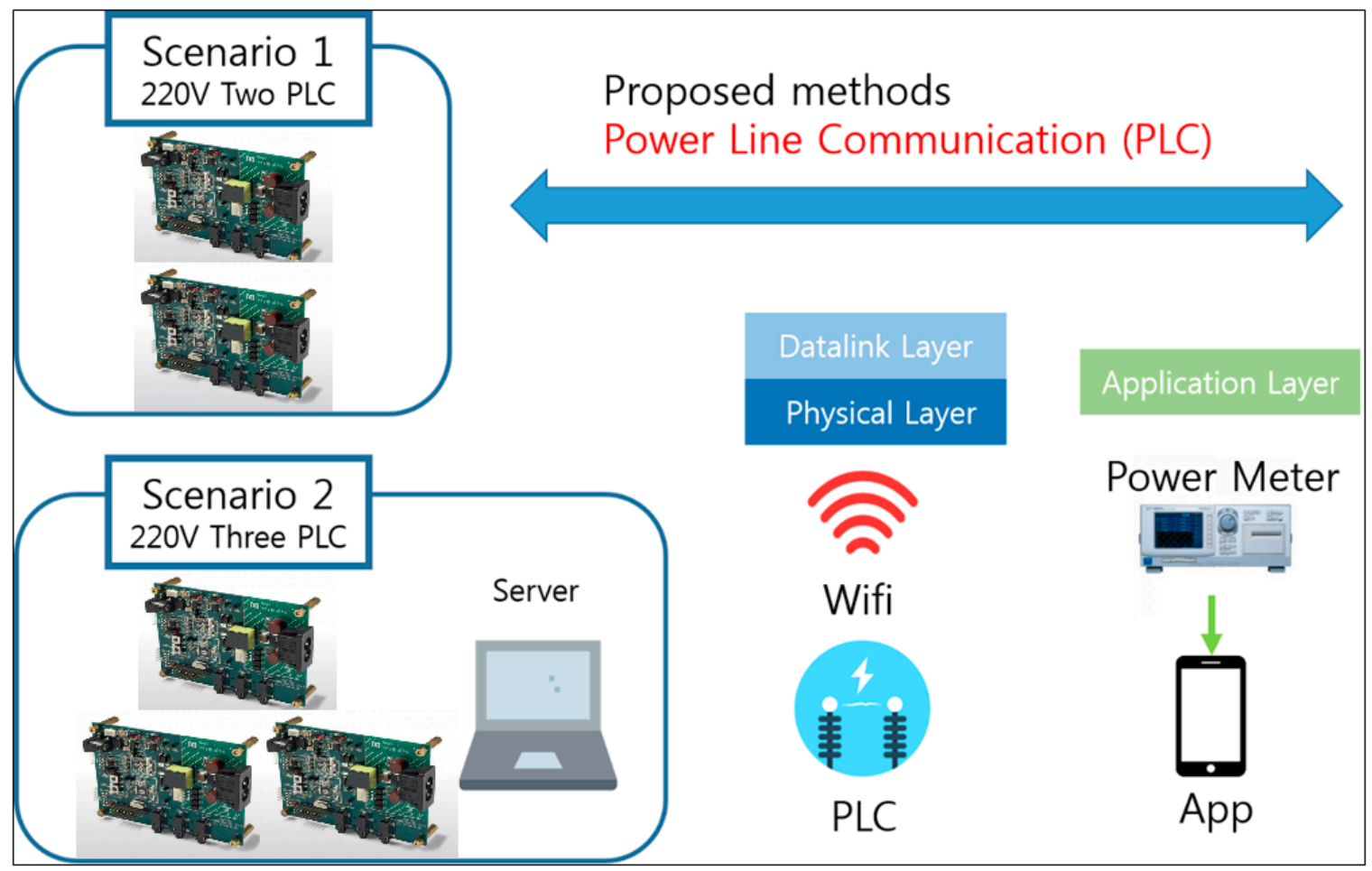

Figure 10. A Framework for Single-Living Senior Citizens Care System.

Also, the Medicine Intake Notification System previously developed [10] described in Figure 11 is embedded in the monitoring system. This notification system was designed to reduce the possibility of side effects caused by mixed-use or abuse of medicines. The author has witnessed such incidents while observing patients with high blood pressure or osteoporosis at hospitals in the Republic of Korea $(\mathrm{ROK})$ and recognized that it is not easy for solitary senior citizens to keep the prescribed dosages regularly or continuously monitor their intake habits due to the costs involved. 


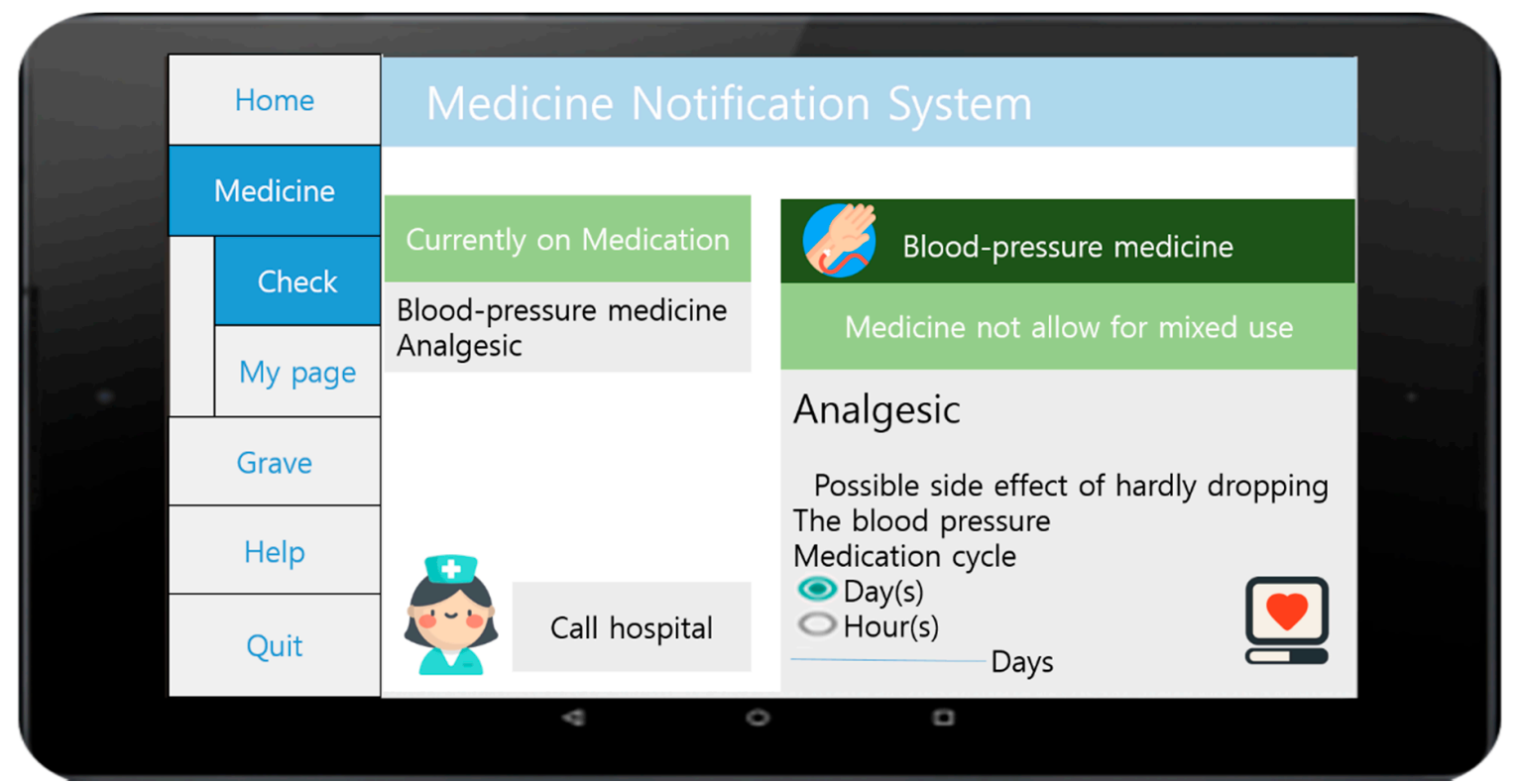

Figure 11. Intake Notification System Implemented via App.

Figure 12 shows a PLC-based gravesite monitoring system which monitors the smart-system-applied gravesites in a memorial park. Around the world, it is customary to visit one's family or ancestor's graves but many solitary senior citizens have problems when they try to visit even nearby family graves due to their sickness or financial problems. This gravesite monitoring system is able to assist them by providing a continuous or a timely online gravesite visiting feature to satisfy their needs or obligations which are considered as a primary duty of descendants in most Asian countries where there are a number of traditional memorial days seasonally and annually. Despite the differences in cultures, this applies to western countries as well.

The author also noticed that the death rate of solitary senior citizens has risen on these memorial days due to suicide, as some of them could not visit the family graves and perform necessary services. This system might be able to reduce such cases as well.

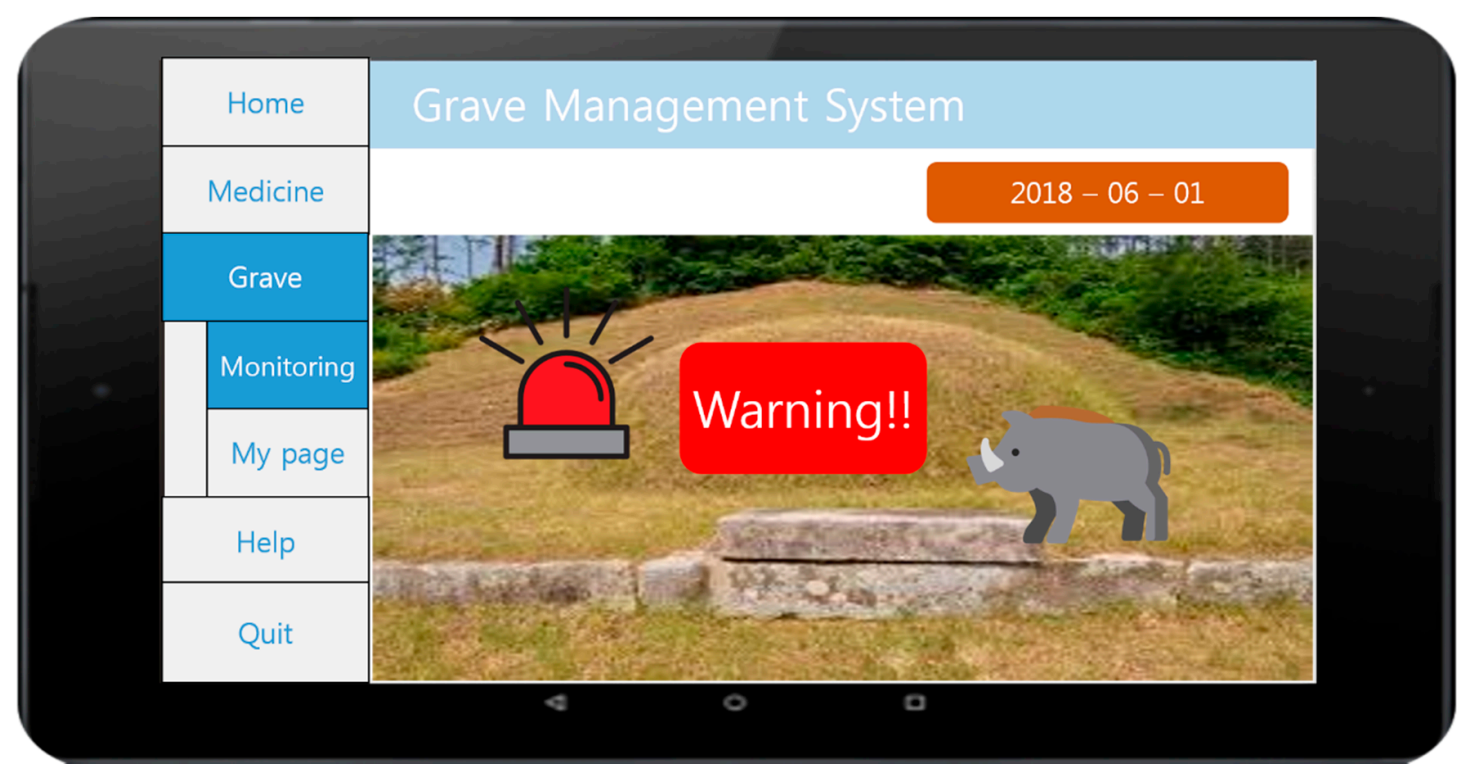

(a)

Figure 12. Cont. 


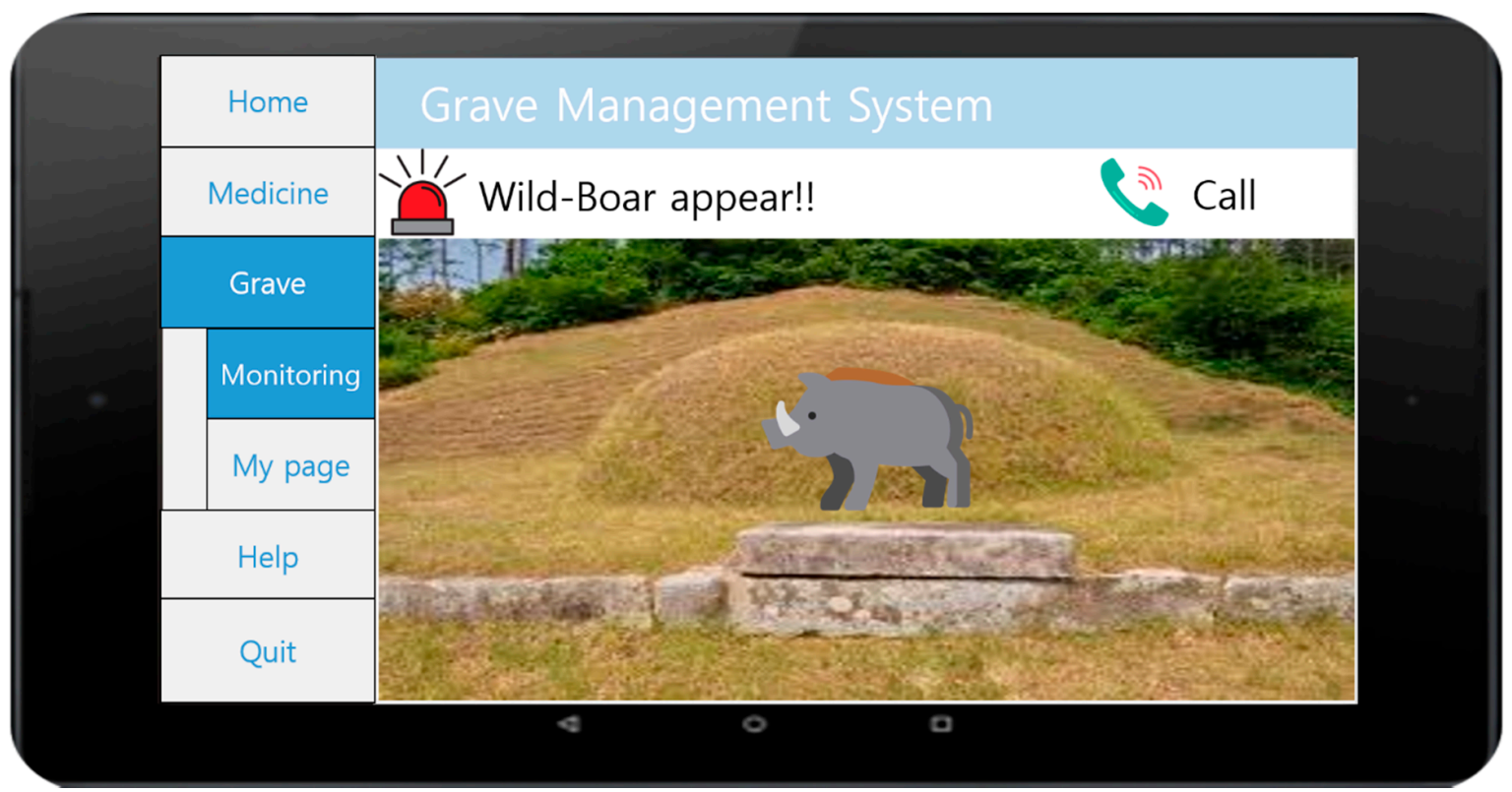

(b)

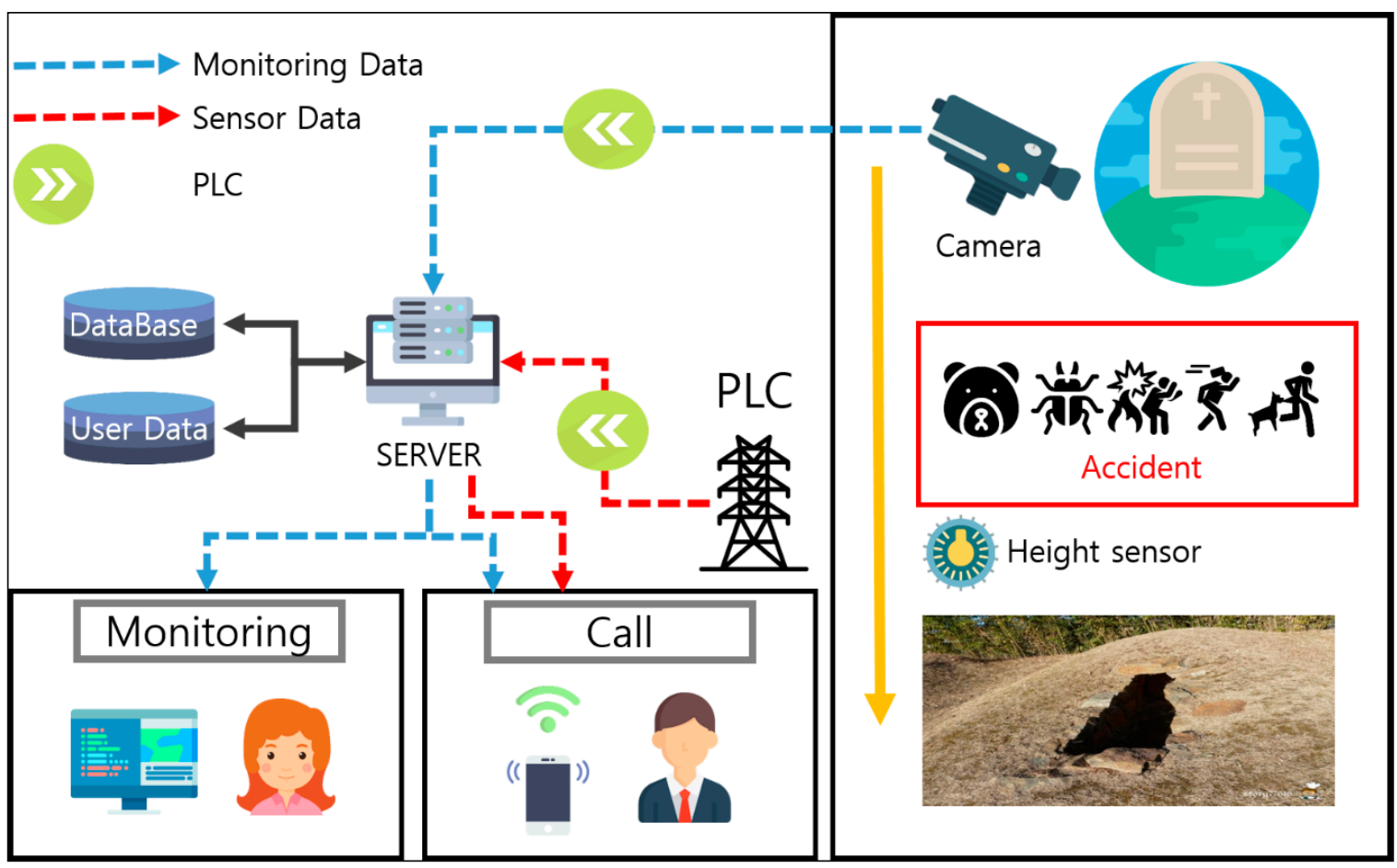

(c)

Figure 12. PLC-based Smart Grave Management System. (a) Grave Management System Application (1). (b) Grave Management System Application (2). (c) Smart Grave Management System.

It is customary that the Koreans visit their parents' gravesites on the traditional holidays but those solitary senior citizens with handicaps often cannot follow such a custom. Thus, I have proposed a smart application with which they will be able to visit the gravesites and take care of their own health by themselves. 


\section{Java Android UML and Application}

Figure 13 describes the entire Java Android-implemented UML of the framework of the solitary senior citizens monitoring system. The user can check the result through the viewer. The range of activity of a solitary senior citizen is checked by each sensor and the collected data is stored on the server. The sensors detect the gas, water, and power usage as well as the illuminance so that each variable name represents an individual element. In the functional formula, the function 'check' refers to the element that a particular sensor specifically monitors. The server delivers information to allow the user to see it through 'View'. For this reason, the variables stored on the server can be seen through the viewer in the same way. When users log into 'Main Activity', they are guided to a 'View' page, after which the users' information is delivered from the server to be displayed via the function 'show_screen'.

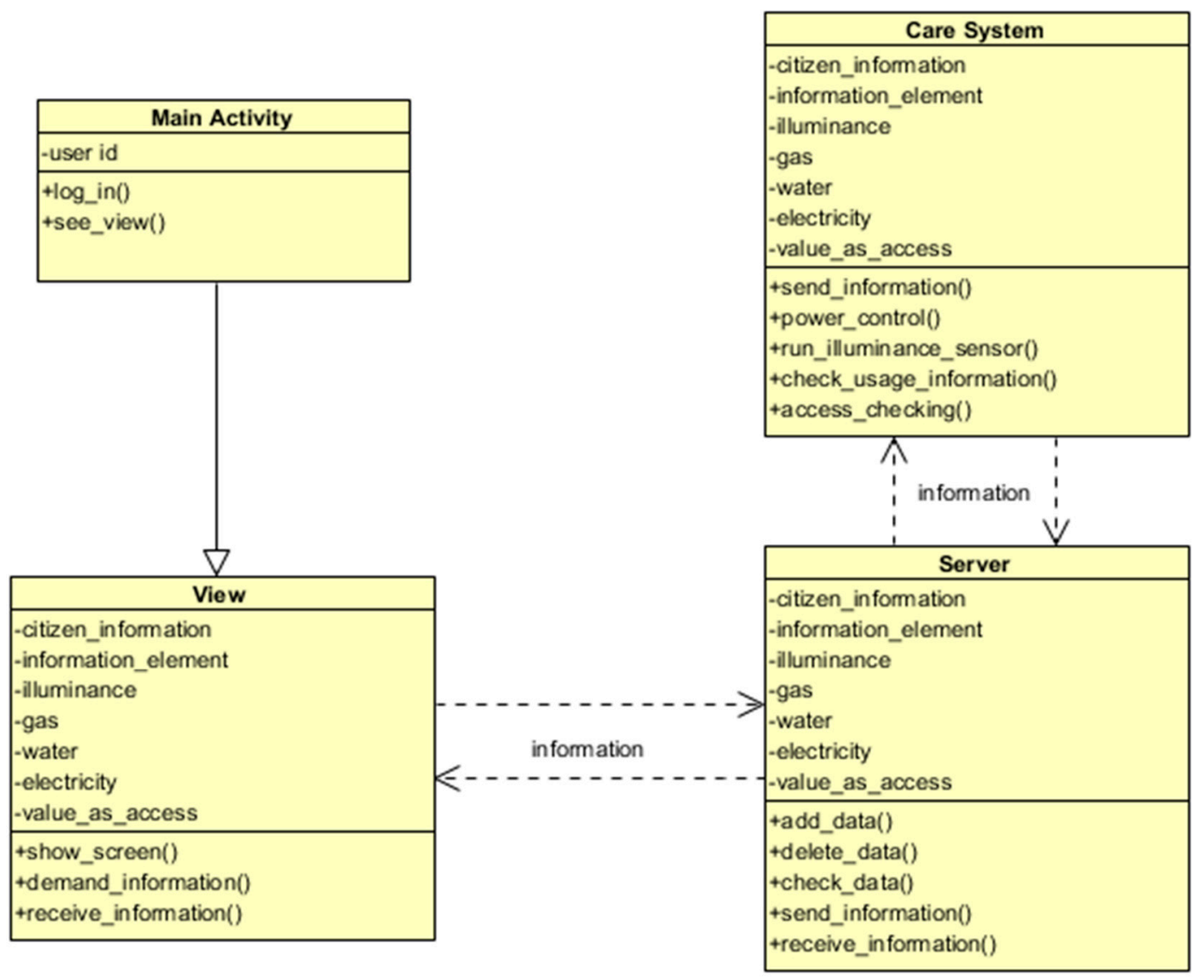

Figure 13. The Entire Java Android-implemented UML of the Framework of Solitary Senior Citizens Monitoring System.

Figure 14 shows the care system Unified Modeling Language (UML) implemented with Java Android. In the entire UML (Figure 13), it was possible to check the information of a solitary senior citizen through the sensor with the function 'check_usage_information' alone. To obtain more information in detail, the user needs to $\log$ in first to initiate the care system which detects the power, water, and gas usage as well as the illuminance and access frequency to determine whether there are any residents in the house. If a person is in the house, the combined data lets the system know about the existence of that person. 'Power Control' checks and adjusts the brightness whereas 'Access Checking' detects the access at the front door with a sensor. 'User Information' detects the utility usage and 'Illumination' detects the intensity of illumination in the house. Then, each class transmits its own information to the server. 


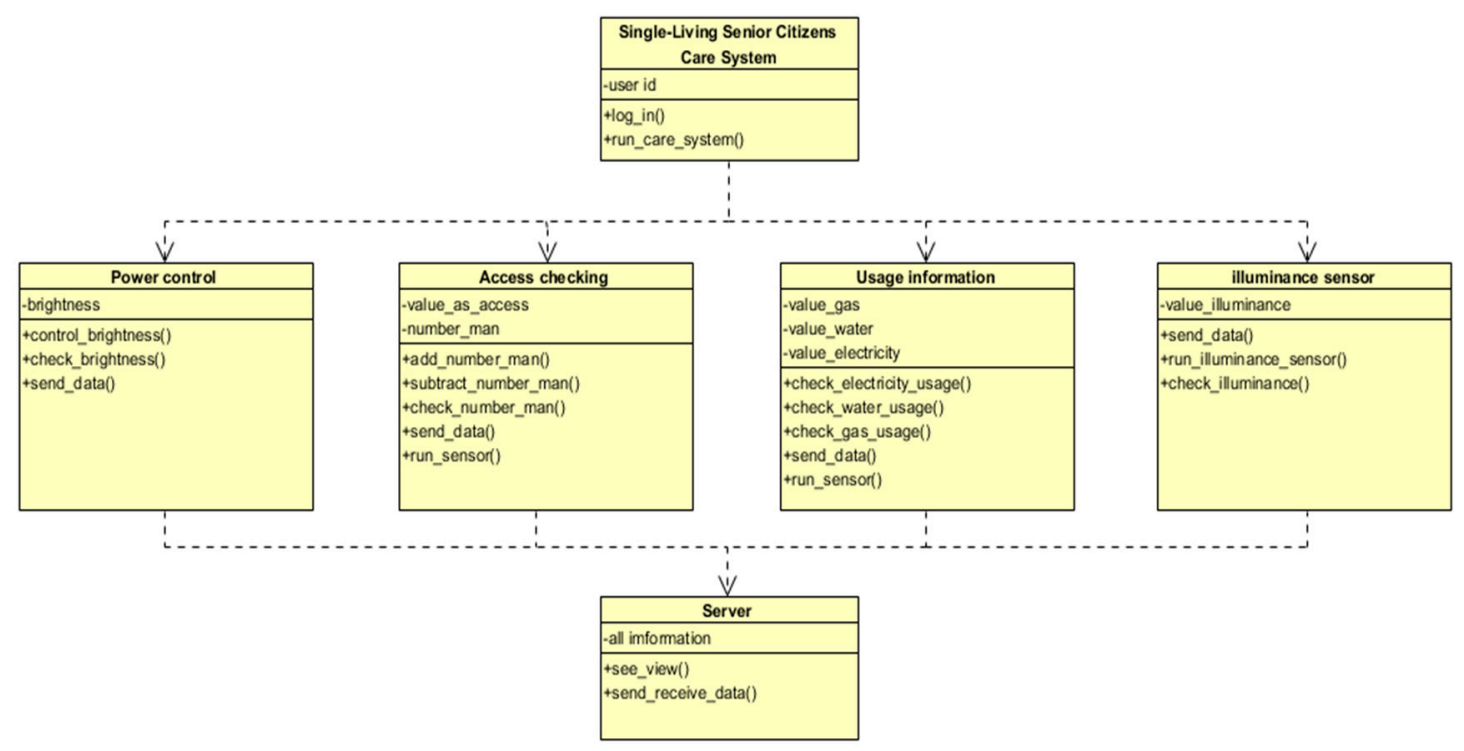

Figure 14. The Care System Unified Modeling Language (UML) Implemented with Java Android.

This application was a safety service for a solitary senior citizen who took a trip on June 5th and 6th. A week's usage can be seen in Figure 15. The usage from June 1st to 7th was represented with a graph and the dates were indicated in the top right. The blue bar represents water usage and the yellow bar represents power usage, whereas the gray bar is for gas usage. The power usage was all ' 0 ' from June 5th to June 6th because of the trip so that it could be marked as 'No one is at home'. The algorithm involving the front door access was used as well.

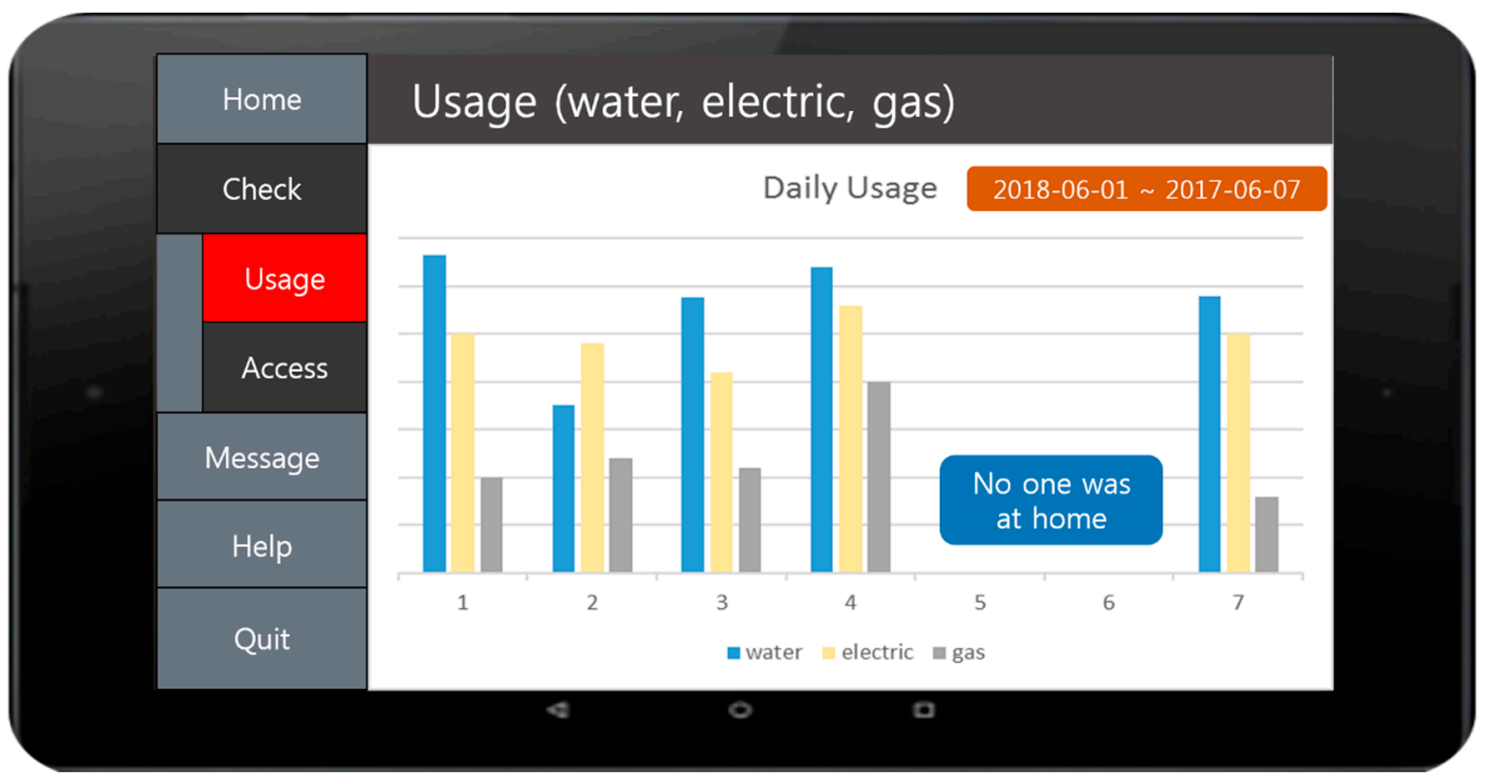

Figure 15. Android Application's User Interface Associated with the Daily Utility Usage Checking.

As in Figure 16, it is possible to check the number of times the front door was accessed and it is graphed every day. Usually, the numbers were high as there were many instances of access, but on June 5th and 6th, the number was ' 0 ' for both such that it could be marked as 'No one is at home'. 


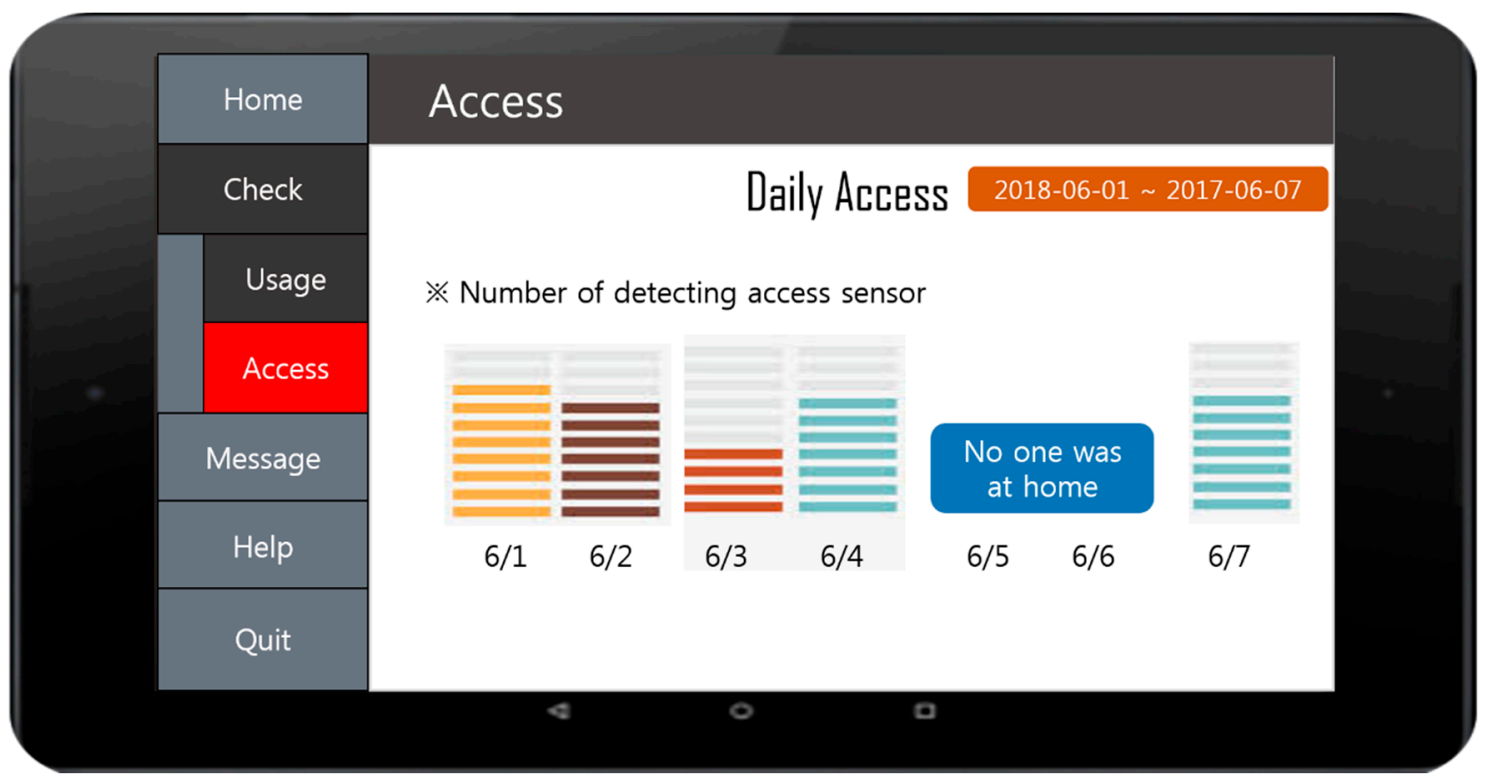

Figure 16. The Front Door Access Detection User Interface of the Proposed Android Application.

Figure 17 is the user interface reporting the current situation and advising a phone call to make sure that no one is at home. June 4th is the first day of the trip so that the sensor values of utility usage and access were all ' 0 ', detecting that the home was vacant. For this, the screen displayed a message advising the designated family member(s) to call their parent as there had not been any detected movements. A function which can call the parent was added in the lower part. This system was implemented as those with Alzheimer's disease often leave their home unwittingly.

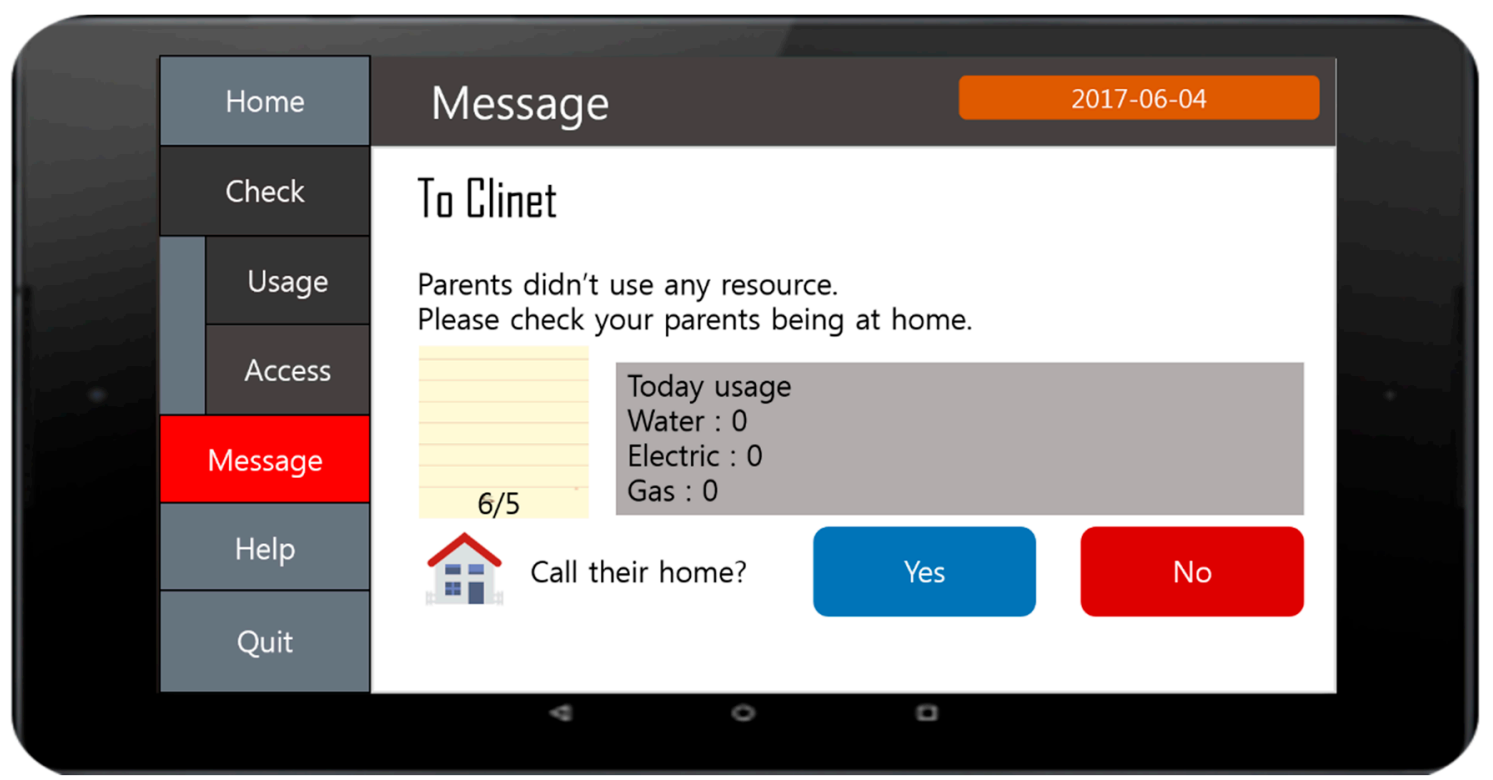

Figure 17. The User Interface for Reporting the Current Situation and Advising a Phone Call.

Figure 18 shows the relief message transmission user interface. The message in the top right mentions that the date is June 8th and the sensors have detected the presence of the parent at home. That is, the message was reassuring the client that the sensors were picking up the movements at home after the scheduled trip on June 5 th and 6th. 


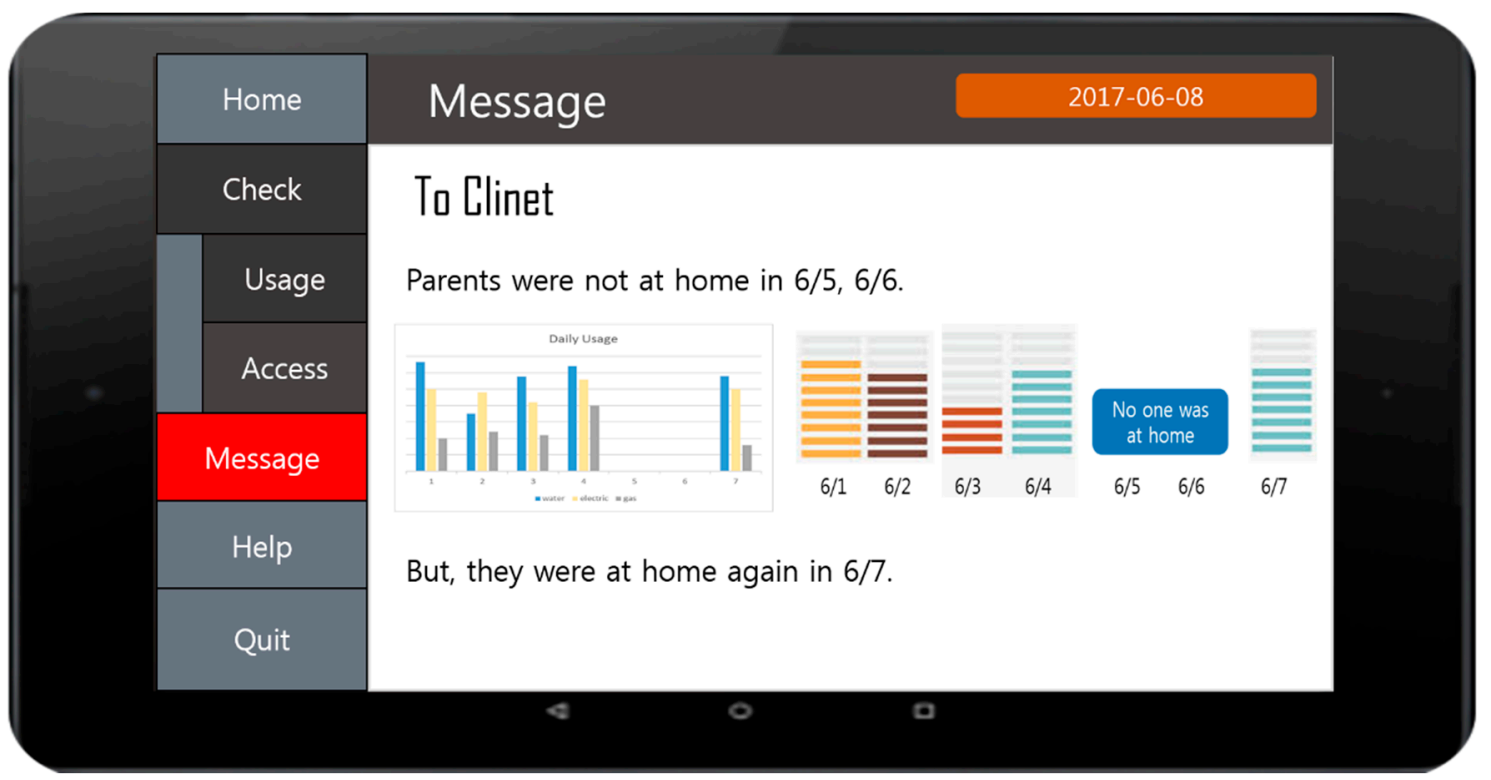

Figure 18. The Relief Message Transmission User Interface.

\section{Conclusions}

In this study, an algorithm which focuses on emotional care has been proposed for a Java-based Android application which pays more attention to the emotional side while monitoring solitary senior citizens rather than just checking on them to determine the life or death situations, as previous similar studies aimed to achieve. A basic framework of a solitary senior citizens care system is introduced in this study which specifically proposes an IoT-integrated, power-consumption-monitoring model utilizing Power Line Communication (PLC) technology. Considering the wide range of possible application areas and its scalability, commercialization can be expected. The test bed experiment for the system has produced some interesting findings while each element in the system interworked flexibly. The framework will also be quite effective for any other applications that focus on solving the problem of unattended deaths of solitary senior citizens.

The introduced system framework effectively monitors the power consumption patterns at the households of solitary senior citizens and for evaluation, a test bed was created. The results obtained from the test bed experiment confirmed that the framework operated flexibly and was effective, scalable, and viable. The respective component designs and implementation methodologies proposed in the study efficiently interworked together. The systems based on this framework can be constructed at low costs without sacrificing any of their functional advantages. Therefore, it is possible that such a monitoring system can be quite useful and effective in the areas where the rate of solitary deaths of senior citizens is higher. The system is also used for monitoring the safety of these people with geriatric diseases or their abnormal behavior patterns which often lead to an unexpected accident or a sudden death.

In the majority of cases, the deaths of solitary senior citizens are discovered too late so that the social costs involved in investigating the cause by police or crime labs are continuously increasing. It is expected that the proposed system will contribute to mitigating such a problem, as well as to solving the problems experienced by small-sized rental housing business operators who lease their homes or rooms to senior citizens. From the test bed experiment and the performance evaluation results, it was possible to confirm that this care service model was effective and efficient in dealing with the emotional aspects of solitary senior citizens while offering the similar functions provided by existing service models.

Again, the test bed results are the only supporting element at this time, but the author would like to emphasize the contribution of this work as a proposal of a new type of care service approach based on the emotional care for solitary senior citizens. The conclusion is limited in some way that further 
research is required to fully validate the approach being proposed. I would like to seek some funding for this effort if possible.

As the primary objective of this study was to propose an effective means of dealing with the solitary deaths of senior citizens, we (Catholic University of Pusan) plan to present this system as an open service program rather than proceeding with commercialization. The code and complete application will be disclosed as an open-source application in our future study.

Funding: This paper was supported by RESEARCH FUND offered from the Catholic University of Pusan in 2018.

Acknowledgments: The first draft of this article was presented in 2016 16th International Conference on Control, Automation and Systems (ICCAS 2016) October 16-19, 2016 at HICO, Gyeongju, Republic of Korea. It was Best Paper Awarded by the Ministry of Trade, Industry and Energy, Republic of Korea [2].

Conflicts of Interest: The author declares no conflict of interest.

\section{References}

1. Vanus, J.; Koziorek, J.; Hercik, R. Design of a Smart Building Control with view to the Senior Citizens' needs. In Proceedings of the 12th IFAC Conference on Programmable Devices and Embedded Systems, the International Federation of Automatic Control, Velke Karlovice, Czech Republic, 25-27 September 2013; pp. 422-427.

2. Huh, J.-H. A Framework and Test Bed for the Single-Living Senior Citizens Care: Access and Grave site Monitorings. In Proceedings of the 2016 16th International Conference on Control, Automation and Systems (ICCAS 2016), Gyeongju, Korea, 16-19 October 2016; IEEE: Piscataway, NJ, USA, 2016; pp. 1-6.

3. Demiris, G.; Rantz, M.; Aud, M.; Marek, K.; Tyrer, H.; Skubic, M.; Hussam, A. Older adults' attitudes towards and perceptions of 'Smart Home' technologies: A pilot study. Med. Inform. Internet Med. 2004, 29, 87-94. [CrossRef] [PubMed]

4. Pattenden, S. CENELEC: Smart House Code of Practice; CWA 50487. Ref. No. CLC/TR; Bruxelles, Belgium, 2005; pp. 50-87. Available online: https:/ / dokumen.tips/documents/cenelec-smarthouse-code-of-practice. html (accessed on 7 November 2018).

5. Zálešák, M. Řízení systémů tvorby prostředí-součást integrovaných řídicích systémů budov (I); Portál TZBinfo.: 2008. Available online: https://www.tzb-info.cz/4421-rizeni-systemu-tvorby-prostredi-soucastintegrovanych-ridicich-systemu-budov-i (accessed on 7 November 2018).

6. Demiris, G. Privacy and Social Implications of Distinct Sensing Approaches to Implementing Smart Homes for Older Adults. In Proceedings of the 2009 Annual International Conference of the IEEE Engineering in Medicine and Biology Society, Minneapolis, MN, USA, 3-6 September 2009; pp. 4311-4314.

7. Koch, S.; Hagglund, M. Health informatics and the delivery of care to older people. Maturitas 2009, 63, 195-199. [CrossRef] [PubMed]

8. Huh, J.H.; Kim, N.; Seo, K. A Study of Power Line Communication-based Smart Outlet System Expandable at Home. J. Korea Multimed. Soc. 2016, 19, 901-909. [CrossRef]

9. Huh, J.H.; Seo, K. Design and Implementation of the Basic Technology for Solitary Senior Citizen's Lonely Death Monitoring System using PLC. J. Korea Multimed. Soc. 2015, 18, 742-752. [CrossRef]

10. Huh, J.H.; Kim, N.; Seo, K. Design and Implementation of Mobile Medication-Hour Notification System with Push Service Function. Int. J. Appl. Eng. Res. 2016, 11, 1225-1231.

11. Census Bureau. The Nation's Older Population is Still Growing; Census Bureau Reports; Census Bureau: Suitland, MD, USA, 2017. Available online: https://www.census.gov/newsroom/press-releases/2017/ cb17-100.html (accessed on 7 November 2018).

12. Eurostat, Population Structure and Ageing. 2017. Available online: http:/ / ec.europa.eu/eurostat/statisticsexplained/index.php/Population_structure_and_ageing (accessed on 27 August 2018).

13. Administration on Aging, a Profile of Older American. 2013. Available online: http://www.aoa.acl.gov / Aging_Statistics/Profile/2013/docs/2013_Profile.pdf (accessed on 27 August 2018).

14. Williams, C.M. Healthy aging and assessing older adults. In Current Diagnosis \& Treatment in Family Medicine, 3rd ed.; South-Paul, J.E., Matheny, S.C., Lewis, E.L., Eds.; The McGraw-Hill Companies: New York, NY, USA, 2011. 
15. Hardy, S.E. Consideration of function \& functional decline. In Current Geriatric Diagnosis and Treatment, 2nd ed.; Williams, B.A., Chang, A., Ahalt, C., Chen, H., Conant, R., Landefeld, C.S., Ritchie, C., Yukawa, M., Eds.; McGraw-Hill: New York, NY, USA, 2014; pp. 3-4.

16. Katz, S. Assessing self-maintenance: Activities of daily living, mobility, and instrumental activities of daily living. J. Am. Geriatr. Soc. 1983, 31, 721-727. [CrossRef] [PubMed]

17. Roley, S.S.; DeLany, J.V.; Barrows, C.J.; Brownrigg, S.; Honaker, D.; Sava, D.I.; Talley, V.; Voelkerding, K.; Amini, D.A.; Smith, E.; et al. Occupational therapy practice framework: Domain \& process. Am. J. Occup. Ther. 2008, 62, 625-683. [PubMed]

18. Foti, D.I.; Koketsu, J.S. Activities of daily living. In Pedretti's Occupational Therapy: Practical Skills for Physical Dysfunction; Elsevier Health Sciences: Amsterdam, The Netherlands, 2013; pp. 157-232.

19. De Werd, M.M.; Boelen, D.; Rikkert, M.G.; Kessels, R.P. Development and evaluation of a clinical manual on errorless learning in people with dementia. Brain Impair. 2015, 16, 52-63. [CrossRef]

20. Votruba, K.L.; Persad, C.; Giordani, B. Patient mood and instrumental activities of daily living in Alzheimer disease. J. Geriatr. Psychiatry Neurol. 2015, 28, 203-209. [CrossRef] [PubMed]

21. Giebel, C.M.; Sutcliffe, C.; Challis, D. Activities of daily living and quality of life across different stages of dementia: A UK study. Aging Ment. Health 2015, 19, 63-71. [CrossRef] [PubMed]

22. Federal Interagency Forum on Aging-Related Statistics. Older Americans 2016: Key Indicators of Well-Being; Federal Interagency Forum on Aging Related Statistics: Washington, DC, USA, 2016.

23. Jekel, K.; Damian, M.; Wattmo, C.; Hausner, L.; Bullock, R.; Connelly, P.J.; Dubois, B.; Eriksdotter, M.; Ewers, M.; Graessel, E.; et al. Mild cognitive impairment and deficits in instrumental activities of daily living: A systematic review. Alzheimers. Res. Ther. 2015, 7, 17. [CrossRef] [PubMed]

24. Fong, T.G.; Gleason, L.J.; Wong, B.; Habtemariam, D.; Jones, R.N.; Schmitt, E.M.; de Rooij, S.E.; Saczynski, J.S.; Gross, A.L.; Bean, J.F.; et al. Inouye, Cognitive and physical demands of activities of daily living in older adults: Validation of expert panel ratings. PMER 2015, 7, 727-735.

25. Singh, I.; Varanasi, A.; Williamson, K. Assessment and management of dementia in the general hospital setting. Rev. Clin. Gerontol. 2014, 24, 205-218. [CrossRef]

26. Chung, J.; Ozkaynak, M.; Demiris, G. Examining daily activity routines of older adults using workflow. J. Biomed. Inform. 2017, 71, 82-90. [CrossRef] [PubMed]

27. Bravo, J.; Cook, D.; Riva, G. Ambient intelligence for health environments. J. Biomed. Inform. 2016, 64, 207-210. [CrossRef] [PubMed]

28. Silva, B.M.; Rodrigues, J.J.; de la Torre Díez, I.; López-Coronado, M.; Saleem, K. Mobile-health: A review of current state in 2015. J. Biomed. Inform. 2015, 56, 265-272. [CrossRef] [PubMed]

29. Roggen, D.; Calatroni, A.; Rossi, M.; Holleczek, T.; Förster, K.; Tröster, G.; Lukowicz, P.; Bannach, D.; Pirkl, G.; Ferscha, A.; et al. Collecting complex activity datasets in highly rich networked sensor environments. In Proceedings of the 2010 Seventh International Conference on Networked Sensing Systems (INSS), Kassel, Germany, 15-18 June 2010; pp. 233-240.

30. Emi, I.A.; Stankovic, J.A. SARRIMA: Smart ADL recognizer and resident identifier in multi-resident accommodations. In Proceedings of the Conference on Wireless Health-WH'15, Bethesda, MD, USA, 14-16 October 2015; ACM Press: New York, NY, USA, 2015; pp. 1-8.

31. Krishnan, N.C.; Cook, D.J. Activity recognition on streaming sensor data. Pervasive Mob. Comput. 2014, 10, 138-154. [CrossRef] [PubMed]

32. Safi, K.; Mohammed, S.; Attal, F.; Khalil, M.; Amirat, Y. Recognition of different daily living activities using Hidden Markov Model regression. In Proceedings of the 2016 3rd Middle East Conference on Biomedical Engineering (MECBME), Beirut, Lebanon, 6-7 October 2016; IEEE: Piscataway, NJ, USA, 2016; pp. $16-19$.

33. Gong, J.; Rose, K.M.; Emi, I.A.; Specht, J.P.; Hoque, E.; Fan, D.; Dandu, S.R.; Dickerson, R.F.; Perkhounkova, Y.; Lach, J.; et al. Home wireless sensing system for monitoring nighttime agitation and incontinence in patients with Alzheimer's disease. In Proceedings of the Conference on Wireless Health-WH'15, Bethesda, MD, USA, 14-16 October 2015; ACM Press: New York, NY, USA, 2015; pp. 1-8.

34. Flores-Vazquez, C.; Aranda, J. Human activity recognition from object interaction in domestic scenarios. In Proceedings of the 2016 IEEE Ecuador Technical Chapters Meeting (ETCM), Guayaquil, Ecuador, 12-14 October 2016; IEEE: Piscataway, NJ, USA, 2016; pp. 1-6.

35. Debes, C.; Merentitis, A.; Sukhanov, S.; Niessen, M.; Frangiadakis, N. A Bauer, Monitoring activities of daily living in smart homes: Understanding human behavior. IEEE Signal Process. Mag. 2016, 33, 81-94. [CrossRef] 
36. Zhu, H.; Chen, H.; Brown, R. A sequence-to-sequence model-based deep learning approach for recognizing activity of daily living for senior care. J. Biomed. Inform. 2018, 84, 148-158. [CrossRef] [PubMed]

37. KERI. Available online: http://www.keri.re.kr/ (accessed on 27 August 2018).

38. Honey HomMed. Available online: http:/ /www.hommed.com/ (accessed on 27 August 2018).

39. Virone, G. Assessing everyday life behavioral rhythms for the older generation. Pervasive Mob. Comput. 2008, 5, 606-622. [CrossRef]

40. Virone, G.; Noury, N.; Demongeot, J. A system for automatic measurement of circadian activity deviations in telemedicine. IEEE Trans. Biomed. Eng. 2002, 49, 1463-1469. [CrossRef] [PubMed]

41. Virone, G.; Alwan, M.; Dalal, S.; Kell, S.W.; Turner, B.; Stankovic, J.A.; Felder, R. Behavioral patterns of older-adults in assisted living. IEEE Trans. Inf. Technol. Biomed. 2008, 12, 387-398. [CrossRef] [PubMed]

42. Lee, S.W. A Circadian Life Pattern Modeling and Anomaly Detection Method for Elders Living Alone. J. KIISE Comput. Pract. Lett. 2011, 17, 399-406.

43. Jang, I.H.; Sim, K.B. Ring-type Heart Rate Sensor and Monitoring system for Sensor Network Application. J. Korean Inst. Intell. Syst. 2007, 17, 619-625. [CrossRef]

44. Lee, Y.G.; Cheon, D.J.; Yoon, G.W. Telemonitoring System of Fall Detection for the Elderly. J. Sens. Sci. Technol. 2011, 20, 420-427. [CrossRef]

45. Kim, N. Development of an Emergency Monitoring Device in a Wrist Watch. J. Korean Inst. Inf. Technol. 2010, 8, 9-17.

46. So, I.M.; Jung, S.T. A Study on the Recognition System of Faint Situation based on Bimodal Information. J. Korea Multimed. Soc. 2010, 13, 225-236.

47. Song, D.H.; Chang, D.J.; Kang, S.H. Development of Lavatory Emergency Detection System using Sensors in Train. J. Korean Soc. Railw. 2011, 14, 341-347. [CrossRef]

48. Jang, J.B.; Park, H.J.; Kim, E.H. A Study on the Protection System for Elderly People Living Alone using Sensor Network. Korea Inf. Process. Soc. 2008, 15, 561-564.

49. Lee, H.J.; Kang, S.J.; Jang, H.G.; Jeong, C.W.; Joo, S.C. Implementation of u-Care System Based on Multi-Sensor in u-Home Environment. J. Korean Soc. Internet Inf. 2011, 12, 135-147.

50. Park, S.H.; Seo, Y.K.; Heo, C.Y.; Jung, S.Y. The Implementation of Emergency Rescue Terminal for the Senior. J. Korea Multimed. Soc. 2012, 15, 195-197.

51. Choi, J.-H. A Silver Life Care System using USN. J. Korean Inst. Inf. Technol. 2008, 6, 37-45.

52. Ko, J.; Shim, J.; Kim, H. Recognition system for emergency situation using Elderly Life Pattern Monitering. J. Korea Contents Assoc. 2012, 15, 443-445.

53. Ko, J.; Kim, H. A Study on the Monitoring System for Emergency Recognition of Elderly People Living Alone. J. KIIT 2014, 12, 61-68. [CrossRef]

54. Huh, J.H.; Koh, T.; Seo, K. A Design of Foundation Technology for PLC-based Smart-grave (Tumulus) System. J. Korea Multimed. Soc. 2015, 18, 1319-1331. [CrossRef]

(C) 2018 by the author. Licensee MDPI, Basel, Switzerland. This article is an open access article distributed under the terms and conditions of the Creative Commons Attribution (CC BY) license (http:/ / creativecommons.org/licenses/by/4.0/). 